\title{
CONTÍNUO RACIAL, MOBILIDADE SOCIAL E "EMBRANQUECIMENTO"
}

\section{Carlos Antonio Costa Ribeiro}

Instituto de Estudos Sociais e Políticos da Universidade do Estado do Rio de Janeiro (Iesp/Uerj), Rio de Janeiro - RJ, Brasil.

E-mail: carloscr@iesp.uerj.br

DOI: $10.17666 / 329503 / 2017$

\section{Introdução}

Atualmente os estudos sobre relaçóes raciais no Brasil enfrentam um dilema importante. Embora estudar as desigualdades e a estratificação racial seja cada vez mais relevante, inclusive para informar as novas propostas de políticas públicas voltadas para a população de não brancos, pesquisas recentes mostram evidências sobre os processos sociais relacionados com a fluidez na classificação de cor ou racial da população (Marteleto, 2012; Schwartzman, 2007; Telles, 2002). Caso não haja uma maneira incontestável de classificar as pessoas de acordo com sua raça ou cor, então não seria possível medir com precisão a desigualdade racial (Loveman, 2011; Muniz, 2010; Telles, 1998). As conclusóes sobre os níveis de desigualdade racial

Artigo recebido em 22/06/2016

Aprovado em 05/04/2017 dependem do tipo de classificação racial adotada. O problema é ainda mais sério quando a estratificação socioeconômica determina a classificação racial - por exemplo, quando ocorre "embranquecimento" das pessoas com mobilidade ascendente - porque nesses casos não é possível ter certeza sobre os mecanismos que levam a desigualdade racial. Em outras palavras, há um problema de causalidade inversa. Em vez de usar a raça ou cor como uma variável independente em modelos estatísticos ou medidas de desigualdade, os pesquisadores estão usando as variáveis de renda, educação e ocupação para explicar a fluidez na classificação racial ou de cor.

Para enfrentar esse dilema, estudo a mobilidade educacional, ocupacional e de renda usando uma nova medida do "contínuo racial" que permite verificar os possíveis efeitos da ambiguidade classificatória nos processos de estratificação. É importante estudar a mobilidade social porque a principal 
questão no debate contemporâneo sobre raça diz respeito a desigualdade de oportunidades, embora a maior parte das evidências analisadas seja sobre desigualdade de condiçóes (Henriques, 2001). A desigualdade socioeconômica, ou de classe, no acesso as oportunidades de mobilidade social está presente em todas as sociedades estudadas até hoje, e no Brasil é especialmente alta (Dunn, 2007; Ishida, 2005). Mas mesmo quando se levam em conta as condiçóes socioeconômicas dos pais observam-se disparidades raciais nos padrôes de mobilidade social e de acesso à educação (Hasenbalg, 1979; 1988; 1999; Silva e Hasenbalg, 1990; Silva, 1992; Telles, 1994; Lovell, 1998; Ribeiro, 2006; Osorio, 2009). A maioria dos estudos usa a dicotomia entre brancos e náo brancos (pretos e pardos) (Hasenbalg, 1979; 1988; 1999; Silva e Hasenbalg, 1990; Silva, 1992; Telles, 1994; Lovell, 1998; Osorio, 2009), mas também há alguns usando as três categorias (Ribeiro, 2006; 2011; Marteleto, 2012) e outros, mais recentes, classificando a cor da pele dos indivíduos a partir de uma paleta de cor usada em pesquisas de opiniáo (Telles, 2014; 2015). A principal conclusão desses trabalhos é que não brancos e principalmente pretos sofrem desvantagens significativas em relação aos brancos. Embora a desigualdade de classe (medida pela classe de origem ou dos pais) seja consideravelmente maior, a raça continua a ser um fator importante na determinação das chances de mobilidade social no Brasil.

Essas evidências poderiam ser severamente criticadas se o dinheiro e a mobilidade ascendente levassem ao "embranquecimento", como sugerem alguns autores (Cardoso, 1960; Degler, 1986; Schwartzman, 2007). Tendo em vista que a raça é definida antes pela aparência do que pela origem, pessoas entre o polo mais claro (branco) e o polo mais escuro (preto) do contínuo de cor ou raça têm mais chances de experimentar fluidez classificatória. Ou seja, têm probabilidades maiores de se apresentarem e serem vistos como mais claros ou mais escuros, o que ocorre mais frequentemente como consequência de sua posição socioeconômica (Telles, 2002; Schwartzaman, 2007). As estratégias de "embranquecimento" ou "escurecimento"1 para obter algum tipo de vantagens são certamente usadas no processo de estratificação, embora sejam relativamente limitadas. De acordo com pesquisas de opinião e pesquisas qualitativas pessoas nos dois extremos do contínuo racial (o mais claro e o mais escuro) não conseguem mudar sua classificação racial (Bailey, 2008; Sansone, 2003).

Assim, o segredo para analisar a relação entre a ambiguidade classificatória e a desigualdade ou a mobilidade é ter uma medida do contínuo racial em vez de uma variável categórica definindo fronteiras rígidas entre grupos raciais. $\mathrm{O}$ primeiro pesquisador que definiu claramente a centralidade do contínuo racial, ou contínuo de aparência racial, no estudo das relaçóes raciais no Brasil, foi o sociólogo Oracy Nogueira, que afirmou no início dos anos de 1960 o seguinte:

O preconceito racial, tal como aqui se apresenta, não tem o mesmo poder que nos Estados Unidos, de dividir a sociedade em dois grupos com consciência própria, como duas castas ou sistemas sociais paralelos, em simbiose, porém, impermeáveis um ao outro, apesar de participarem, fundamentalmente, da mesma cultura. Aqui, o preconceito tende, antes, a situar os indivíduos, uns em relação aos outros, ao longo de um continuum que vai do extremamente "negroide", de um lado, ao completamente "caucasoide", de outro (Nogueira, [1962] 1998, p. 239).

Tendo em vista que a raça no Brasil é definida pela aparência podemos, seguindo Oracy Nogueira, dizer que há um contínuo de características raciais que vai do mais escuro e com traços "negroides" (cabelo, traços faciais etc.) até o mais claro e com traços "caucasianos" ou brancos. Acho importante ressaltar que esse contínuo pode ser tanto de cor da pele como de outras características físicas ou raciais e, nesse sentido, vou usar ao longo do artigo o termo "contínuo racial". Assim, o estudo das desigualdades no Brasil precisa levar em conta esse contínuo racial para realmente entender os mecanismos que produzem desvantagens raciais. Até mesmo a ideia de que é possível mudar de um grupo racial para outro náo faz muito sentido, porque o que provavelmente ocorre é que as pessoas se movem 
um pouquinho para cima ou para baixo no contínuo racial, ou seja, não mudam inteiramente de um grupo racial para outro. A partir dessa constatação, Nogueira (Idem) desenvolve teoricamente o argumento de que as relaçóes raciais no Brasil estão mais próximas da ideia weberiana de hierarquia de status do que da ideia de grupos fechados, tais como castas (Weber, [1922] 1978). O fato de o grau de fechamento ser menor no Brasil do que nos Estados Unidos, po exemplo, não significa que o preconceito, a discriminação e outros mecanismos de exclusão baseados na raça não sejam relevantes para criar desigualdades. O principal desafio para a pesquisa quantitativa contemporânea é investigar a relação entre a ambiguidade classificatória e a desigualdade racial tanto no Brasil quanto em outros países (Alba, 2003; Harris, 2002; Keith, 1991; Loveman, 2007; Nobles, 2000; Telles, 1990; 2009; Villarreal, 2011; Xie, 1997).

Neste artigo, proponho uma abordagem do contínuo racial baseada na ideia de que as respostas, obtidas em uma pesquisa de opiniấo, às perguntas aberta (escolha dos entrevistados) e fechada (categorias do Censo Demográfico) sobre raça ou cor podem ser combinadas. A metodologia que uso para elaborar o contínuo racial é semelhante à utilizada em estudos recentes sobrem hierarquias de status, que elaboram índices de status baseados nos padróes de amizade (Machado, 2015) ou de casamento (Salata, 2016) em termos ocupacionais. Argumento, portanto, que a perspectiva de Oracy Nogueira, ao sugerir que a estratificação racial é uma espécie de estratificação de status e não de classe ou de casta, encontra respaldo metodológico na abordagem que adoto. Nesse sentido, em vez de tratar a inconsistência classificatória como um erro ou ambiguidade, o que é usual na literatura (Muniz, 2012; Silva, 1994; 1996; 2012; Telles, 2004), argumento que as respostas às duas perguntas (aberta e fechada) podem ser combinadas para construir uma medida "latente" (não observada diretamente) do contínuo racial, semelhante a um contínuo de status social. Além disso, o índice que elaboro também permite determinar em que pontos da escala racial a ambiguidade classificatória têm mais probabilidade de ocorrer. Essa característica do contínuo racial é usada para fa- zer simulaçóes "contrafactuais" com o objetivo de analisar os possíveis efeitos do "embranquecimento pelo dinheiro" no estudo da desigualdade de oportunidades. Esse tipo de desigualdade é mensurado usando modelos para estimar as chances de mobilidade educacional, ocupacional e de renda. Embora meu interesse principal seja o efeito do contínuo racial nas transferências intergeracionais, também estimo os efeitos de diversas variáveis medindo as condiçóes socioeconômicas da família de origem, tais como educação e ocupação dos pais entre outras características. As análises usam dados coletados pela Pesquisa Dimensóes Sociais das Desigualdades (PDSD) realizada em 2008.

$\mathrm{O}$ artigo está dividido em sete partes, sendo a primeira esta introduçáo. $\mathrm{Na}$ segunda parte discuto brevemente alguns aspectos relevantes das relações raciais no Brasil. $\mathrm{Na}$ terceira apresento os dados e os métodos. Na quarta descrevo como elaborei a variável para o contínuo racial. $\mathrm{Na}$ quinta apresento os resultados sobre desigualdade de oportunidades em termos ocupacionais, educacionais e de renda. A sexta parte apresenta as simulaçóes para testar os possíveis efeitos da ambiguidade classificatória e do "embranquecimento" nos resultados apresentados na seção anterior. $\mathrm{Na}$ última parte discuto os resultados e conclusóes.

\section{Estratificação racial no Brasil}

Embora o contínuo racial seja uma construção social baseada na definição da raça em termos da aparência física em vez da origem racial (Nogueira, [1962] 1998), também é uma consequência dos casamentos inter-raciais. Se não houvesse casamento inter-racial não haveria contínuo racial. No Brasil, a não existência de leis segregacionistas, o tamanho da população de origem africana (muito grande) e a imigração em larga escala de europeus no início do século XX contribuíram para que houvesse um número relativamente alto de casamentos inter-raciais. De acordo com o sociólogo Peter Blau (1984), se os casamentos inter-raciais e a segregação espacial fossem aleatórios países com populações racialmente mais homogêneas - em que não há um grupo racial predominante como é o caso brasileiro - teriam altos níveis de casamento inter-racial e baixos 
níveis de segregação racial. De fato, alguns estudos concluem que há menos segregação residencial (espacial) e mais casamentos inter-raciais no Brasil do que nos Estados Unidos, mas também mostram que os padróes no Brasil não são aleatórios (Ribeiro, 2009; Silva, 1987; Telles, 1992; 1993). A principal conclusão no primeiro tópico é que os níveis de segregação espacial (brancos versus não brancos) são moderados nos bairros e regióes de classes mais baixas e que os bairros mais ricos são predominantemente brancos (Telles, 1992). Quando comparados com os Estados Unidos, os níveis de segregação espacial em termos raciais no Brasil são entre baixos e moderados. Além disso, a proximidade residencial entre brancos e não brancos facilita a sociabilidade, as relaçóes de amizade e até mesmo os casamentos entre pessoas com diferentes características. De fato, no segundo tópico, as principais conclusóes são que as barreiras ao casamento inter-racial estão diminuindo ao longo do tempo (Ribeiro, 2009), são mais fracas na região Nordeste (Silva, 1992; Telles, 1993) e mais fluidas entre brancos e pardos do que entre pardos e pretos (Ribeiro, 2009; Silva, 1987). Além disso, há algumas evidências de troca de status, na medida em que homens pretos e pardos mais educados tendem a se casar com mulheres brancas menos educadas (Ribeiro, 2009; Silva, 1987). Embora casamentos inter-raciais sejam mais comuns no Brasil do que nos Estados Unidos, também há barreiras fortes na primeira sociedade, mesmo quando se leva em conta fatores socioeconômicos como a educação alcançada (Ribeiro, 2009). No entanto, as taxas elevadas de casamentos inter-raciais no âmbito agregado (um em cada dez em 1960 crescendo para um em cada três em 2000) contribuem para o nascimento de muitos filhos e filhas com diferentes características raciais. Tendo em vista que a raça é definida pela aparência física e não pela ancestralidade, crianças nascidas com diferentes características raciais são encontradas não apenas entre famílias, mas também dentro das mesmas famílias. De fato, o casamento inter-racial é uma poderosa forma de produzir pessoas com características raciais misturadas e, portanto, é o que cria o contínuo racial em última instância.

O contínuo racial torna mais provável a ocorrência da ambiguidade classificatória. Argumento neste artigo que mensurar o efeito do continuo racial, em vez do efeito de variáveis categóricas opondo duas (brancos versus não brancos) ou três (branco, pardo e preto) categorias de cor ou raça, é uma abordagem alternativa para estudar a desigualdade racial e melhor para entender os possíveis efeitos da ambiguidade classificatória no Brasil. Além disso, sugiro que a chave para avançar o conhecimento sobre as relaçóes raciais no Brasil é estudar o contínuo racial de forma direta. De acordo com Silva (1987) e Telles (2004), o "enigma das relaçóes raciais no Brasil" é entender porque e como as "relações horizontais", ou sociabilidade racial, são relativamente fluidas enquanto as "relaçóes verticais", ou processos de estratificação, são muito mais rígidas. Uma maneira melhor de mensurar o contínuo racial parece ser um fator chave para reconciliar os resultados aparentemente opostos dos estudos sobre sociabilidade e estratificação racial. A partir de uma medida do contínuo racial é possível entender a fluidez tanto na seletividade marital quanto na mobilidade social, ou em qualquer outro aspecto das "relações horizontais e verticais". De acordo com a literatura contemporânea, em termos de desigualdade socioeconômica pardos estão mais próximos de pretos (Hasenbalg, 1988; Osório, 2009) e, em termos de casamentos, pardos estão mais próximos de brancos (Silva, 1987; Ribeiro, 2009). Essas evidências indicam que os efeitos do contínuo racial são diferentes nesses dois fenômenos, mas também que estão presentes em ambos. Em vez de pensar em termos de barreiras ou fronteias raciais, os cientistas sociais poderiam pensar em termos dos usos, reaçóes e sensibilidades às aparências raciais em vários tipos de relaçôes sociais. De fato, pesquisas etnográficas indicam que esse tipo de interpretação faz perfeito sentido no Brasil, ou pelo menos na Bahia (Sansone, 1996). Esta é uma maneira distinta de conceber as relações raciais. Seguindo uma longa tradição de estudos sobre relaçóes raciais no Brasil, argumento que em vez de construir a raça em termos categóricos, como grupos autossuficientes, os brasileiros (e talvez outros) estratificam por raça em termos de um "contínuo de características raciais" que se assemelha a um contínuo de status social. Quan- 
to mais escura e "negroide" for a pessoa maior a discriminação e o preconceito que sofre, e menores suas chances de escamotear suas características físicas. De fato, estudos recentes têm dado mais atenção para os efeitos de medir raça de diferentes formas na mensuração dos níveis de desigualdade (Loveman, 2011; Telles, 1998), por um lado, e para o fato de que as escolhas de classificação racial que os indivíduos fazem serem estratégias no processo de estratificação (Schwartzman, 2007), por outro lado.

O primeiro grupo de pesquisadores afirma que diferentes formas de construir a variável de raça ou cor levam a conclusóes dispares sobre os níveis de desigualdade racial. Telles e Lin (1998), por exemplo, argumentam que a desigualdade racial de renda é mais alta quando os entrevistadores classificam a cor ou raça dos entrevistados do que quando os respondentes se autoclassificam. Mais recentemente, Loveman, Muniz e Bailey (2011) mostraram que os níveis de desigualdade de renda variam significativamente quando os respondentes se autoclassificam nas três categorias do Censo Demográfico do que quando as categorias preto e pardo são combinadas arbitrariamente (uma prática comum em pesquisas quantitativas que usam a variável cor ou raça no Brasil) e quando aqueles que inicialmente se classificaram como pardos têm a opção de se classificar novamente, agora como negros ou como brancos. Eles concluem que seria melhor manter a classificação tradicional usando três categorias em vez de adotar uma classificação binária forçada ou de combinar pretos e pardos em uma única categoria. Além disso, há pesquisas indicando que pessoas que se definem como pardas são mais propensas à classificação ambígua ao longo do contínuo de cor ou racial (Bailey, 2008).

O que esses estudos (Loveman, 2011; Muniz, 2010; Silva, 2012; Telles, 1998) indicam é que a metodologia usada para construir a variável de raça ou de cor da pele (autoclassificação em uma pergunta aberta, autoclassificação em categorias fechadas, combinação arbitrária entre pardo e preto, perguntas com só duas categorias, identificação com fotografias, identificação pelo entrevistador, paleta de cor, identificação por origem social etc.) pode levar a conclusóes muito dispares sobre as desigualdades e outros temas de interesse. Este é um problema sério para o estudo da desigualdade racial. Uma solução sugerida por alguns autores (Saperstein, 2008) é combinar mais de uma questão de pesquisas imaginando que todas são medidas imperfeitas de raça ou de etnia. Em outras palavras, perguntas e outros instrumentos usados em pesquisas de opiniáo poderiam ser pensados como formas imperfeitas de se medir um conceito ou uma variável "latente". Por exemplo, quando psicólogos querem medir a "depressão" eles usam uma série de questóes e a partir do padrão observado nas respostas inferem escalas latentes para medir o conceito de depressáo. Reconhecendo que a aparência é um aspecto crítico para definir a raça no Brasil, proponho neste artigo uma medida do contínuo racial baseada na combinação das respostas a uma pergunta aberta (em que os respondentes escolhiam livremente uma categoria de cor ou raça para se definir) e a outra pergunta fechada (preto, pardo ou branco) sobre raça ou cor. Minha proposta não é verificar erros de classificação entre as duas respostas, como tem sido usual em muitas pesquisas (Muniz, 2012; Silva, 1994; 1996; 2012; Telles, 2004), mas usar ambas para estimar uma variável latente para medir o contínuo racial. Alguns outros pesquisadores propuseram tipos semelhantes de abordagem para medir a raça em outros países (Burton, 2010; Saperstein, 2008).

Embora minha abordagem não seja perfeita (nenhuma é), argumento e mostro que ela tem vantagens em relação à prática corrente de usar variáveis categóricas - seja juntando pretos e pardos em uma única categoria, seja usando os três termos, branco, pardo e preto. Além disso, minha abordagem permite tratar diretamente de outro tema importante ressaltado pela literatura sobre relaçóes raciais: o efeito das condiçóes socioeconômicas e da mobilidade social na classificação racial ou da cor da pele. Degler (1986), por exemplo, argumenta que mulatos e pardos que alcançam posiçóes socioeconômicas mais altas tendem a se apresentar e a serem vistos como mais claros (a clássica hipótese do mulatto escape hatch). Em um artigo mais recente, Schwartzman (2007) mostra que filhos e filhas de casais inter-raciais com educação de nível superior têm mais chances de serem classificados pelos pais como brancos do que filhos de casais 
semelhantes com menos anos de escolaridade. Em outras palavras, a autora mostra evidências contundentes confirmando a hipótese de que o dinheiro pode levar ao "embranquecimento" e que a pobreza pode levar ao "escurecimento". Esses estudos sugerem que a classificação racial é uma estratégia usada pelos indivíduos no processo de estratificação social, ou seja, o "embranquecimento" é provavelmente uma estratégia usada pelos indivíduos que procuram alcançar mobilidade ascendente. De fato, estudos sobre "ambiguidade classificatória" e/ ou "embranquecimento" usam modelos estatísticos que invertem a ordem causal usual, porque empregam variáveis medindo condiçóes socioeconômicas para explicar a "classificação racial" ao invés de usar a raça como uma variável independente. Essa inversão é um desafio para a pesquisa sobre desigualdade racial porque, se for verdade, como parece ser, torna-se difícil mensurar a desigualdade racial per se. Por exemplo, se pessoas mais escuras que alcançam posiçóes mais altas nas hierarquias de estratificação (renda, ocupação e educação) tendem a se "embranquecer" (escondem seus sinais de negritude) os níveis de desigualdade racial estão provavelmente sobre estimados. Neste artigo uso a variável de contínuo racial para analisar as possíveis consequências do "embranquecimento" na mensuração da mobilidade social em termos de educação, status ocupacional e renda. Mais especificamente, uso, na sexta seção do artigo, a variável de contínuo racial que construí para fazer exercícios "contrafactuais" que permitem testar os efeitos do "embranquecimento" nas medidas de desigualdade de oportunidades.

Estudos anteriores sobre desigualdade de oportunidades no Brasil focalizaram o efeito das condiçóes socioeconômicas dos pais na mobilidade educacional e socioeconômica (status ocupacional, renda e bem-estar) dos filhos. A maioria dos estudos sobre estratificação educacional e mobilidade social enfoca a comparação entre brancos e não brancos (Hasenbalg, e Silva, 1990; 1999; Lovell, 1998; Hasenbalg, 1979; 1988; 1999; Osorio, 2009; Silva, 1992; Telles, 1994), mas há também alguns estudos que usam as três categorias (preto, pardo e branco) e chegam a conclusóes bastante interessantes (Ribeiro, 2006; Torche, 2012). Em geral, esses estudos que usam as três categorias mostram que brancos têm vantagens em relação a pardos e estes em relação a pretos; ou seja, as vantagens parecem estar distribuídas hierarquicamente ao longo dos grupos raciais. Um desses estudos mostra que há interação entre classe e raça para indivíduos com origens de classe mais altas, mas não para indivíduos com origens de classe mais baixas (Ribeiro, 2006). Mais recentemente, uma série de estudos usou uma classificação exógena (feita pelo entrevistador) do contínuo de cor para concluir que as desvantagens socioeconômicas estão correlacionadas à cor da pele, ou seja, quanto mais escuro for o indivíduo, piores suas chances de vida (Telles, 2014; 2015). Em suma, há evidências de que o contínuo racial é uma boa maneira de interpretar a estratificação racial no Brasil.

\section{Dados, variáveis e métodos}

\section{Dados}

Neste artigo uso dados da PDSD, que é uma pesquisa amostral representativa da população brasileira rural e urbana, com exceção da parte rural da região Norte, que conta com apenas 3,3\% da população. Coletada entre outubro e novembro de 2008, a PDSD é uma amostra de 8048 domicílios, tendo seguido um procedimento de seleção probabilística em três estágios. Primeiro, foram selecionados os municípios, depois as microrregióes censitárias dentro dos municípios e, por fim, os domicílios. Informaçôes básicas sobre educaçáo e emprego foram coletadas para todos os membros dos domicílios selecionados com 10 anos ou mais de idade. Um grande número de questôes, incluindo informaçóes retrospectivas sobre os pais dos respondentes, foi feito para chefes e cônjuges em todos os domicílios. Para as análises desenvolvidas neste artigo uso uma amostra que incluí chefes $\mathrm{e}$ cônjuges entre 30 e 64 anos de idade que eram ativos na força de trabalho no mês em que foram entrevistados. Também selecionei apenas os indivíduos que se declararam brancos, pardos e pretos, ou seja, exclui os amarelos $(1,1 \% \mathrm{da}$ amostra) e os indígenas $(1,7 \% \mathrm{da}$ amostra). Ao final, todas essas restrições resultam em uma amostra de 6886 indivíduos.

Como é comum em pesquisas com informações retrospectivas sobre os pais, há um número considerá- 
vel de casos com informaçóes faltantes para as variáveis descrevendo as características parentais. Se todos esses casos com informaçôes faltantes para educação e ocupação dos pais fossem excluídos, cerca de $40 \%$ da amostra seria eliminada, o que poderia levar a estimativas errôneas. Para não perder esses casos usei um método de imputação múltipla desenvolvido por King (2001). Esse procedimento pressupóe que os dados faltantes são aleatórios (missing at random - MAR), isto é, assume que levando em conta uma série de variáveis correlacionadas não há seletividade nos padróes de informação faltante (missing values).

\section{Variáveis}

Examino a associação entre raça e três variáveis dependentes: educação alcançada, status ocupacional e renda. A educação é mensurada pelos anos de escolaridade completos, o status ocupacional pelo International Socio-Economic Index (Isei) (Ganzeboom, Graaf e Treiman, 1992), e a renda pelo logaritmo dos rendimentos líquidos mensais do trabalho.

A raça é medida de duas formas. Primeiro, uso as variáveis dicotômicas tradicionais (branco, pardo e preto) e, depois, uma variável para o contínuo racial estimada por um modelo log-linear para linhas e colunas ordenadas chamado RC-2 (Goodman, 1984). Esse modelo foi ajustado à tabela cruzando as respostas aberta e fechada sobre raça - na próxima seção explico melhor como a escala foi construída com base nesse modelo.

Controlo por diversas características dos pais quando os respondentes estavam crescendo, ou melhor, quando tinham aproximadamente 15 anos de idade: educaçáo do pai e da mãe (em anos de estudo completos), status ocupacional do pai e da mãe (Isei) e se os pais eram proprietários da casa em que viviam. Tendo em vista que mais da metade das mães dos respondentes não estava no mercado de trabalho, incluí uma variável dicotômica com valor 1 para as mães que não trabalhavam com o objetivo de manter esses casos na amostra. Para medir a estrutura familiar usei outra variável dicotômica com valor 1 para os respondentes que viviam com ambos os pais aos 15 anos de idade e 0 para outros arranjos familiares. Além disso, os modelos incluem variáveis de controle para idade (e idade ao quadrado) do respondente, sexo, e regiáo de residência (Sul, Sudeste, Norte, Nordeste e Centro-Oeste). Estatísticas descritivas para todas estas variáveis são apresentadas na Tabela 1.

\section{Métodos}

Usei dois tipos de modelos estatísticos: um modelo log-linear para linhas e colunas (RC-2) que estima uma variável latente para o contínuo racial (ver próxima seção); modelos de regressão linear por mínimos quadrados para estimar a educação alcançada, o status ocupacional e a renda do trabalho dos indivíduos (ver quinta seção). ${ }^{2}$ Também usei uma técnica de simulação estatística para obter as probabilidades preditas apresentadas na Figura 2 (King, 2000). Por fim, para analisar os possíveis efeitos do "embranquecimento" nas chances de mobilidade, estimei diversas regressóes usando uma variável para raça em que indivíduos com renda alta e categoria racial ambígua foram artificialmente "escurecidos" (explico melhor esse procedimento na sexta seção).

\section{Uma nova classificação para o contínuo racial}

Para resolver o "enigma das relaçóes raciais" no Brasil é fundamental ter uma medida do contínuo racial que permita uma descrição precisa das desigualdades. Na década de 1980 e 1990, quando se iniciaram os estudos quantitativos sobre relaçóes raciais no Brasil, Carlos Hasenbalg e Nelson do Valle Silva (Hasenbalg, 1979; 1988; Hasenbalg e Silva, 1992; 1999; Hasenbalg, Lima e Silva, 1999) tinham pressa para mostrar que havia desigualdade racial alta e persistente e, portanto, adotaram uma classificação binária para raça (brancos versus não brancos). Desde que essas primeiras evidências estatísticas foram apresentadas, passou a ser prática comum o uso de classificaçóes dicotômicas para a raça no Brasil. Até mesmo agências do governo, como o Instituto de Pesquisas Econômicas Aplicadas (Ipea), têm usado a dicotomia branco versus "negro" (pardos mais pretos), que é o termo preferido pelo movimento negro. ${ }^{3}$ Mais recentemen- 
te, muitos estudos vêm mostrando que diferentes maneiras de medir raça levam à conclusóes muito dispares sobre os níveis de desigualdade (Loveman, 2011; Muniz, 2010; Telles, 1998). Enquanto essa literatura enfatiza os prováveis erros de classificação na mensuração da variável cor ou raça, proponho neste artigo uma outra abordagem. Argumento que diferentes perguntas sobre raça ou cor obtidas em pesquisas de opinião podem ser combinadas para mensurar uma escala latente do contínuo racial (Saperstein, 2008; 2011).

$\mathrm{Na}$ parte superior da Tabela 1 apresento o cruzamento das variáveis aberta e fechada para a autoclassificação racial obtida a partir do questionário da PDSD. ${ }^{4} \mathrm{Na}$ pergunta aberta os respondentes podiam usar qualquer classificaçáo de cor da pele que desejassem, enquanto na pergunta fechada tinham de escolher uma das três categorias do Censo (branco, pardo ou preto). Primeiro, foi feita a pergunta aberta e depois a fechada. ${ }^{5}$ Sugiro que a combinação de ambas as respostas pode ser usada para estimar uma variável contínua em que a raça é classificada entre valores mudando ao longo de uma escala que vai do bem claro e branco ("caucasoide") até o bem escuro e preto ("negroide").

Os dados da Tabela 1 indicam que as pessoas que se classificam como pretos (ou negros), pardos e brancos na pergunta aberta tendem a se classificar na mesma categoria na pergunta fechada. Essas respostas consistentes às duas perguntas são válidas para $65,7 \%$ de todos os entrevistados. Além disso, um grande número de pessoas tende a se classificar como "moreno" na pergunta aberta. Várias outras categorias foram usadas para responder à pergunta aberta, todas variando ao longo de um contínuo de cor ou raça que vai do mais escuro e negro ao mais claro e branco.

Em vez de tratar a diferença entre as repostas às perguntas aberta e fechada como erros de classificação, como é usual na literatura (Loveman, 2011; Muniz, 2010; Silva, 1994; 1996; 2012; Telles, 1998), uso os dados da Tabela 1 para estimar um contínuo racial baseado no grau e no padrão de associação entre as duas variáveis para cor ou raça (aberta e fechada). Para analisar o padrão de associação usei o modelo log-linear RC-2 de Goodman (1984), que estima a distância entre categorias nas linhas e nas colunas de uma tabela cruzada de acordo com o padrão de associação entre ambas. Tendo em vista que há uma tendência para classificação nas mesmas categorias em ambas as respostas (branco/branco, preto/preto/negro e pardo/ pardo), também incluí no modelo parâmetros para levar em conta esta tendência - esses parâmetros são semelhantes aos termos para capturar a "imobilidade" na análise de tabelas de mobilidade social (Hout, 1983).

O modelo com essas especificaçôes se ajusta bem aos dados de acordo com a estatística BIC $(-27,6)$ e, portanto, o padrão de associação e as escalas para linhas e colunas obtidas são significativas. Como esperado, o modelo indica que as chances de classificação consistente em ambas as respostas explicam grande parte da associação. As combinaçóes preto/preto, negro-preto, pardo/pardo e branco/ branco são 6,7 vezes mais prováveis do que qualquer outra combinação de respostas. Esses resultados indicam que a classificaçáo na mesma categoria é bastante consistente.

O modelo, apresentado na parte inferior da Tabela 1, também revela que as escalas estimadas para linhas (respostas à pergunta aberta) e colunas (resposta à pergunta fechada) estão fortemente associadas (associação igual a 11,3). Essas escalas também são apresentadas na parte superior da Tabela 1. A soma das escalas para linhas e colunas é usada para construir uma escala conjunta combinando todas as categorias em uma única hierarquia, que pode ser interpretada como uma medida latente do contínuo racial, ou seja, de um contínuo de características raciais que vai do mais escuro e negro para o mais claro e branco, tendo no meio pessoas com diferentes níveis de características brancas ou negras tais como cor da pele, cabelo, nariz etc. Essa escala hierárquica ordena de forma substantivamente significativa todas as células da tabela cruzando a classificação aberta e a fechada de raça (o alfa de Cronbach para essa escala conjunta é de 0,84 , o que é altamente significativo). A escala é relevante porque classifica todas as pessoas numa ordenação válida tendo em um dos extremos aqueles que se classificaram como pretos em ambas as respostas e no outro extremo as pessoas que se classificaram em ambas como brancos. 
Tabela 1

Autoclassificaçáo Racial em Questóes Aberta e Fechada (Homens e Mulheres Entre 30 e 64 Anos de Idade)

Parte 1

\begin{tabular}{|c|c|c|c|c|c|}
\hline \multirow[t]{3}{*}{ Questáo Aberta } & \multirow[b]{3}{*}{ Escala RC-2 } & \multicolumn{4}{|c|}{ Questáo Fechada } \\
\hline & & Preto & Pardo & Branco & Total \\
\hline & & $-1,846$ & $-0,844$ & 2,690 & \\
\hline Preta & $-1,872$ & 193 & 17 & 1 & 210 \\
\hline Negra & $-1,283$ & 324 & 56 & 1 & 381 \\
\hline Morena escura & $-1,163$ & 11 & 9 & 1 & 21 \\
\hline Mulata & $-0,793$ & 6 & 12 & 0 & 18 \\
\hline Marrom & $-0,148$ & 2 & 5 & 0 & 7 \\
\hline Parda & 0,117 & 37 & 1023 & 21 & 1081 \\
\hline Sarará & 0,194 & 4 & 0 & 2 & 6 \\
\hline Morena & 0,204 & 196 & 1329 & 205 & 1730 \\
\hline Morena clara & 0,513 & 17 & 162 & 77 & 255 \\
\hline Castanho & 0,620 & 0 & 2 & 1 & 4 \\
\hline Canela & 0,681 & 0 & 3 & 2 & 5 \\
\hline Jambo & 0,682 & 0 & 0 & 0 & 1 \\
\hline Clara & 1,116 & 1 & 16 & 65 & 82 \\
\hline Branca & 1,132 & 23 & 78 & 2984 & 3086 \\
\hline Total & & 814 & 2712 & 3360 & 6886 \\
\hline
\end{tabular}

Fonte: Pesquisa Dimensōes Sociais das Desigualdades, 2008. Elaboração do autor.

Parte 2

Modelo Para Dados Acima: RC-2 Mais Estimadores Para Classificaçóes Iguais em Ambas as Perguntas, Linhas e colunas com escalas diferentes

Modelo de linhas e colunas heterogêneas (RC-2 model)

$\mathrm{L}^{2}$

Índice de dissimilaridade

Graus de liberdade

Número de parâmetros

BIC

\begin{tabular}{ll}
\hline Ajuste & p-value \\
\hline 69,60 & 0,000
\end{tabular}

0,014

11

$30(+1)$

$-27,6$

\begin{tabular}{lll} 
& & p-value \\
\cline { 3 - 3 } Parâmetros estimados & Coef. & 0,0 \\
\hline Associaçáo & 11,3 & 0,0 \\
\hline "Imobilidade" & 1,9 &
\end{tabular}

Fonte: Pesquisa Dimensóes Sociais das Desigualdades, 2008. Elaboração do autor. 
As pessoas que se classificaram como pardas em ambas ficam no meio da escala. Os que se classificaram entre essas combinaçóes na mesma categoria vão dos mais escuros para os mais claros. Assim, a soma das escalas para linhas e colunas revela uma escala latente estatística e substantivamente significativa para o "continuo racial". Essa interpretação estatística está de acordo com uma longa tradição de estudos nas ciências sociais brasileiras, sugerindo que a o contínuo racial é uma característica importante das relaçóes raciais no país. Como mencionei na introdução, Oracy Nogueira ([1962] 1998) foi o primeiro sociólogo a afirmar claramente que o preconceito racial no Brasil era baseado na aparência e não na origem ou na ancestralidade (como nos Estados Unidos). Inspirado nessa tradição proponho uma medida para o contínuo racial baseada nos resultados obtidos pelo modelo apresentado na Tabela 1. A Figura 1 apresenta a variável elaborada.
De acordo com essa escala, 7,5\% dos respondentes se classificam como preto/preto ou negro/ preto, 5,7\% estão entre preto/preto e pardo/pardo, $14,9 \%$ estão na categoria pardo/pardo, $28,5 \%$ estão entre pardo/pardo e branco/branco e $43,3 \%$ estão na categoria branco/branco. A escala tem duas propriedades importantes: está na ordem correta em termos do contínuo racial e permite classificar $34 \%$ de todas as pessoas em categorias intermediárias entre branco e pardo e entre pardo e preto. Essas categorias intermediárias são dominadas por combinaçôes do termo "morena" ("morena", "morena clara" e "morena escura") na questão aberta e pelos termos tradicionais (branco, pardo e preto) na questão fechada. Por fim, a escala tem duas vantagens em relação às categorias tradicionais: amplia significativamente as possibilidades de classificação racial e classifica os indivíduos ao longo de uma escala ordenada. O próximo passo é verificar como a escala se comporta nos modelos usados para estimar a mobilidade social.

Figura 1

Contínuo de Cor da Pele Obtido Pelo Modelo RC-2 (apresentado na Tabela 1)

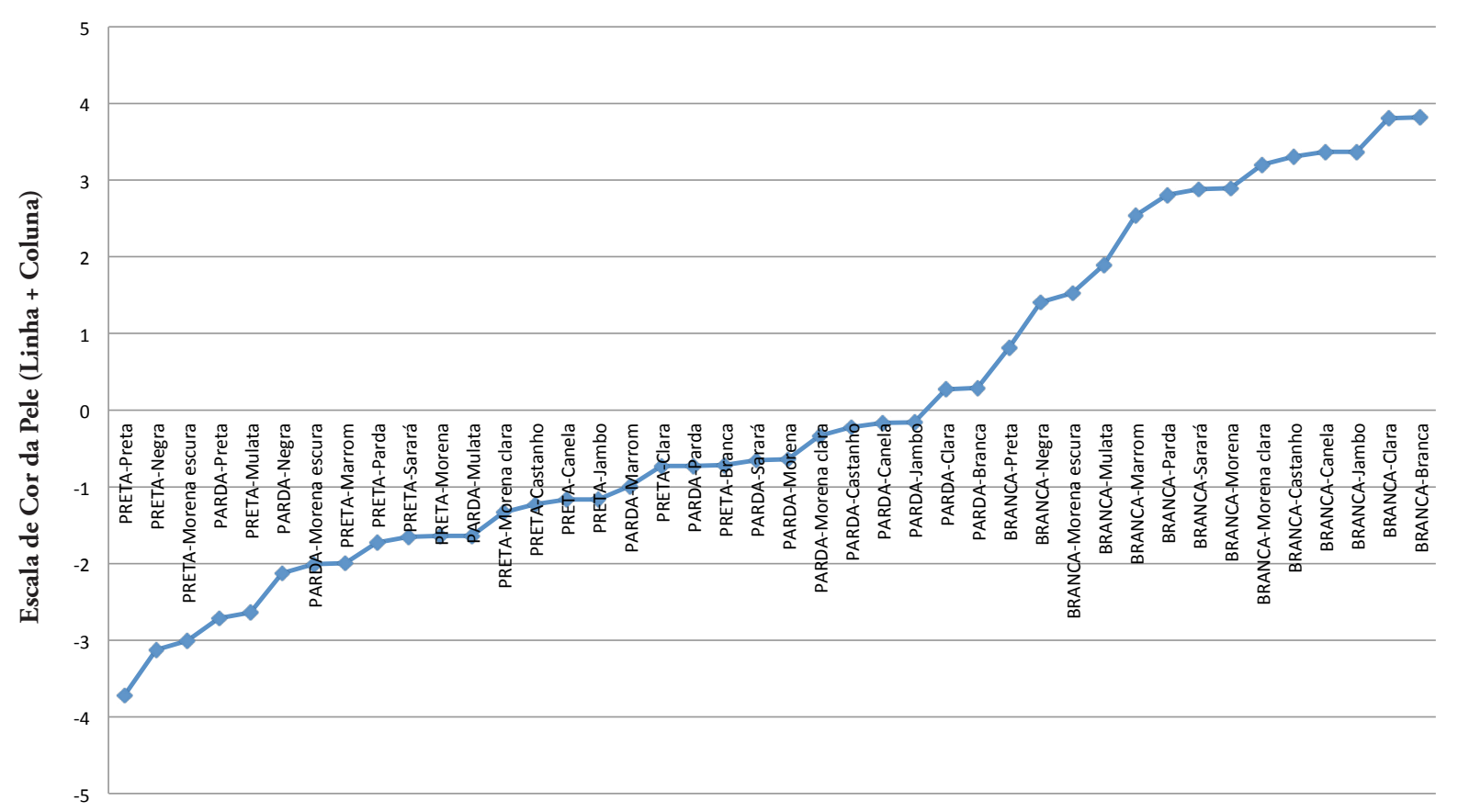

Fonte: Pesquisa Dimensões Sociais das Desigualdades, 2008. Elaboração do autor. 


\section{Resultados}

Para estudar o processo de estratificaçáo racial estimei modelos de regressão linear para analisar a mobilidade social em termos de anos de escolaridade completos, status ocupacional (por meio do International Socio-Economic Index of Occupational Status - Isei) e logaritmo da renda do trabalho. Meu foco é no efeito da raça nas chances de mobilidade, mas os modelos também incluem variáveis para controlar pelo efeito do sexo do respondente, da idade (e idade ao quadrado), da educação dos pais, do status ocupacional dos pais, da estrutura familiar, da propriedade do domicílio dos pais, da área de residência (rural ou urbana) em que viveu até os 15 anos de idade, além da região atual de residência (Sudeste, Nordeste, Norte, Sul e Centro-Oeste). Para a renda e o status ocupacional do respondente também estimei modelos com e sem a variável para os anos de educaçáo alcançados, que é a principal variável mediando as características da família de origem e o status ocupacional ou a renda. Todos os modelos são apresentados em duas versóes: uma usando a variável para o contínuo racial (apresentado na Figura 1) e outra usando a variável categórica tradicional para raça (branco, pardo e preto). Essas análises têm dois objetivos: o primeiro é comparar a maneira tradicional de medir cor ou raça (usando variáveis categóricas) com a medida do contínuo racial que apresentei na seção anterior; a segunda é avançar de forma consequente a ideia de que a escala de raça, em vez das categorias de raça per se, é um fator significativo no processo de estratificação no Brasil. O primeiro objetivo é explicitamente metodológico, simplesmente porque é um teste de uma nova forma de medir raça, enquanto o segundo é teórico porque sugere que raça no Brasil náo deve ser pensada categoricamente, como grupos em oposição, mas sim como uma hierarquia. Como argumentei, a possibilidade de se mover entre posiçóes ao longo do contínuo racial pode ser uma estratégia usada pelas pessoas no regime de estratificação brasileiro. Na próxima seção apresento algumas simulaçōes para testar os possíveis efeitos do "embranquecimento" nos resultados apresentados nesta seção.

A Tabela 2 apresenta todos os modelos estimados para analisar os efeitos da raça no processo de estratificação. A primeira observação que destaco é que as duas maneiras de usar a variável (categórica ou continua) são equivalentes tendo em vista que o ajuste geral dos modelos (R2) e os efeitos de todas as variáveis independentes são praticamente os mesmos. No entanto, os modelos com a escala racial contínua são mais simples do que os outros, ou seja, usam apenas um grau de liberdade para estimar o efeito da raça. Além disso, quando a variável categórica é usada a diferença entre os efeitos de pardos e pretos não é estatisticamente significativa para os modelos 1,7 e 9. Esse fato não ocorre quando a escala continua de raça é usada nos modelos equivalentes 2 , 8 e 10 .

As análises sobre educaçáo revelam que os respondentes que tinham maiores chances de alcançar mais anos de escolaridade eram as mulheres, pessoas cujos pais tinham status ocupacional alto e mais anos de educação, indivíduos que cresceram com o pai e a mãe casados e viviam em domicílio próprio, que viveram em áreas urbanas até os 15 anos de idade e não viviam no Nordeste. Levando em conta todas essas características, os indivíduos que se autoclassificaram como brancos na questão fechada (Modelo 1) atingiam em média 0,74 anos de escolaridade a mais do que aqueles que se classificaram como pardos ou pretos; ${ }^{6}$ e indivíduos que se classificaram como branco em ambas as questôes, aberta e fechada (modelo 2), atingiam em média 0,57 mais anos de escolaridade do que aqueles que se classificaram em ambas como pardo (pardo/pardo) e 0,95 mais do que os que se classificaram em ambas como preto (preto/preto). ${ }^{7}$ Tendo em vista que a média de anos de estudo é 7,43 e que controlei os efeitos de raça por diversas outras características, essas diferenças são realmente grandes. Embora ambas as maneiras de estimar a desigualdade racial sejam válidas, o uso da escala racial, no Modelo 2, mostra que os indivíduos no meio (pardo/pardo) têm chances melhores de alcançar mais anos de escolaridade do que aqueles na ponta mais escura da escala racial (preto/preto). Essa diferença não pode ser observada a partir do Modelo 1, que usa a classificação de raça tradicional (categórica). Uma vez que a variável contínua (Modelo 2) possibilita uma descrição mais precisa da desigualdade racial, concluo que usá-la é melhor do que adotar a estratégia tradicional, que usa a variável categórica. 
Tabela 2

Modelos de Regressáo Linear (OLS) Para Anos de Escolaridade, Status Ocupacional (Isei) e Log da Renda do Trabalho (Brasileiros Entre 30 e 64 Anos de Idade)

\section{Modelos usando variáveis categóricas para "cor da pele"}

\begin{tabular}{|c|c|c|c|c|c|c|c|c|c|c|c|c|c|c|c|}
\hline & \multicolumn{3}{|c|}{ Modelo 1} & \multicolumn{3}{|c|}{ Modelo 3} & \multicolumn{3}{|c|}{ Modelo 5} & \multicolumn{3}{|c|}{ Modelo 7} & \multicolumn{3}{|c|}{ Modelo 9} \\
\hline & \multicolumn{3}{|c|}{$\begin{array}{l}\text { Anos de } \\
\text { Escolaridade }\end{array}$} & \multicolumn{3}{|l|}{ Isei } & \multicolumn{3}{|c|}{$\begin{array}{l}\text { Isei }+ \text { Anos de } \\
\text { Escolaridade }\end{array}$} & \multicolumn{3}{|c|}{$\begin{array}{l}\text { Ln(Renda do } \\
\text { Trabalho) }\end{array}$} & \multicolumn{3}{|c|}{$\begin{array}{l}\text { Ln(Renda do } \\
\text { Trabalho) + Anos } \\
\text { de Escolaridade }\end{array}$} \\
\hline & Coef. & & $\mathrm{DP}$ & Coef. & & $\mathrm{DP}$ & Coef. & & $\mathrm{DP}$ & Coef. & & $\mathrm{DP}$ & Coef. & & $\mathrm{DP}$ \\
\hline Branco & 0,736 & $* * *$ & 0,163 & 1,959 & $* *$ & 0,636 & 0,866 & & 0,581 & 0,183 & $* * *$ & 0,050 & 0,107 & $*$ & 0,047 \\
\hline Pardo & 0,101 & & 0,163 & 1,408 & * & 0,621 & 0,258 & & 0,569 & 0,058 & & 0,050 & 0,048 & & 0,047 \\
\hline Anos de escolaridade & & & & & & & 1,484 & $* * *$ & 0,055 & & & & 0,103 & $* * *$ & 0,004 \\
\hline Homem & $-0,154$ & & 0,101 & 1,757 & $* * *$ & 0,385 & 1,986 & *** & 0,357 & 0,396 & *** & 0,030 & 0,412 & $* * *$ & 0,029 \\
\hline Idade & 0,125 & * & 0,054 & 0,537 & $* *$ & 0,202 & 0,352 & & 0,189 & 0,049 & $* *$ & 0,016 & 0,037 & * & 0,015 \\
\hline Idade $^{2}$ & $-0,002$ & $* *$ & 0,001 & $-0,005$ & $*$ & 0,002 & $-0,002$ & & 0,002 & $-0,001$ & $* *$ & 0,000 & 0,000 & $*$ & 0,000 \\
\hline Status ocup. do pai (ISEI) & 0,045 & * & 0,005 & 0,183 & $* * *$ & 0,021 & 0,117 & *** & 0,020 & 0,009 & *** & 0,001 & 0,004 & $* *$ & 0,001 \\
\hline Status ocup. da mãe (ISEI) & 0,022 & $* *$ & 0,007 & 0,098 & $* *$ & 0,034 & 0,066 & * & 0,031 & 0,003 & & 0,002 & 0,000 & & 0,002 \\
\hline Educação do pai & 0,175 & $* * *$ & 0,018 & 0,445 & $* * *$ & 0,072 & 0,185 & $* *$ & 0,067 & 0,034 & *** & 0,005 & 0,016 & $* *$ & 0,005 \\
\hline Educaçấo da mãe & 0,272 & $* * *$ & 0,020 & 0,692 & $* * *$ & 0,081 & 0,288 & $* * *$ & 0,076 & 0,038 & *** & 0,006 & 0,010 & & 0,005 \\
\hline Estrutura familiar & 0,917 & $* * *$ & 0,120 & 1,873 & $* * *$ & 0,425 & 0,512 & & 0,398 & 0,102 & ** & 0,036 & 0,007 & & 0,034 \\
\hline Pais c/ casa própria & 0,516 & *** & 0,113 & 1,789 & $* * *$ & 0,424 & 1,023 & $* *$ & 0,391 & 0,126 & *** & 0,034 & 0,073 & * & 0,032 \\
\hline Mãe trabalhava & $-0,399$ & $* * *$ & 0,103 & $-1,214$ & $* *$ & 0,394 & $-0,623$ & & 0,366 & $-0,066$ & $*$ & 0,031 & $-0,025$ & & 0,029 \\
\hline Norte (vs. Nordeste) & 0,793 & $* * *$ & 0,221 & 0,695 & & 0,775 & $-0,481$ & & 0,731 & 0,250 & $* *$ & 0,073 & 0,168 & $* *$ & 0,066 \\
\hline Sudeste ( $v s$. Nordeste) & 0,558 & *** & 0,134 & 0,356 & & 0,472 & $-0,472$ & & 0,440 & 0,616 & *** & 0,041 & 0,558 & $* * *$ & 0,039 \\
\hline Sul (vs. Nordeste) & 0,188 & & 0,157 & 0,174 & & 0,538 & $-0,105$ & & 0,493 & 0,534 & *** & 0,047 & 0,514 & $* * *$ & 0,044 \\
\hline $\begin{array}{l}\text { Centro-Oeste } \\
\text { (vs. Nordeste) }\end{array}$ & 1,227 & $* * *$ & 0,214 & 2,033 & $*$ & 0,831 & 0,213 & & 0,740 & 0,640 & $* * *$ & 0,061 & 0,513 & $* * *$ & 0,055 \\
\hline $\begin{array}{l}\text { Área urbana até } \\
15 \text { anos }\end{array}$ & 1,939 & $* * *$ & 0,117 & 3,426 & $* * *$ & 0,402 & 0,549 & & 0,388 & 0,073 & * & 0,034 & $-0,127$ & $* * *$ & 0,034 \\
\hline Constante & $-0,462$ & & 1,251 & 2,215 & & 4,701 & 2,900 & & 4,411 & 3,685 & $* * *$ & 0,367 & 3,733 & $* * *$ & 0,352 \\
\hline $\mathrm{N}$ & 6886 & & & 6886 & & & 6886 & & & 6886 & & & 6886 & & \\
\hline $\mathrm{F}$ & 219,2 & & & 64,61 & & & 109,9 & & & 76,47 & & & 111,2 & & \\
\hline Prob. > F & 0 & & & 0 & & & 0 & & & 0 & & & 0 & & \\
\hline R-quadrado & 0,388 & & & 0,2205 & & & 0,343 & & & 0,199 & & & 0,291 & & \\
\hline
\end{tabular}

Fonte: Pesquisa Dimensóes Sociais das Desigualdades, 2008. Elaboração do autor 


\section{Continuaçáo Tabela 2}

Modelos de Regressão Linear (OLS) Para Anos de Escolaridade, Status Ocupacional (Isei) e Log da Renda do Trabalho (Brasileiros Entre 30 e 64 Anos de Idade)

\section{Modelos usando variável contínua para “cor da pele"}

\begin{tabular}{|c|c|c|c|c|c|c|c|c|c|c|c|c|c|c|c|}
\hline & \multirow{2}{*}{\multicolumn{3}{|c|}{$\begin{array}{l}\text { Modelo } 2 \\
\text { Anos de } \\
\text { escolaridade }\end{array}$}} & \multirow{2}{*}{\multicolumn{2}{|c|}{$\begin{array}{l}\text { Modelo } 4 \\
\text { Isei }\end{array}$}} & & \multirow{2}{*}{\multicolumn{3}{|c|}{$\begin{array}{l}\text { Modelo } 6 \\
\text { Isei + anos de } \\
\text { Escolaridade }\end{array}$}} & \multirow{2}{*}{\multicolumn{3}{|c|}{$\begin{array}{l}\text { Modelo } 8 \\
\text { Ln (renda do } \\
\text { trabalho) }\end{array}$}} & \multirow{2}{*}{\multicolumn{3}{|c|}{$\begin{array}{l}\text { Modelo } 10 \\
\text { Ln (Renda do } \\
\text { Trabalho) + anos } \\
\text { de escolaridade }\end{array}$}} \\
\hline & & & & & & & & & & & & & & & \\
\hline & \multicolumn{2}{|l|}{ Coef. } & \multirow{2}{*}{$\frac{\mathrm{DP}}{0,021}$} & \multicolumn{2}{|l|}{ Coef. } & \multirow{2}{*}{$\frac{\mathrm{DP}}{0,082}$} & \multirow{2}{*}{$\frac{\text { Coef. }}{0,021}$} & \multirow{2}{*}{\multicolumn{2}{|c|}{$\frac{\mathrm{DP}}{0,075}$}} & \multicolumn{2}{|l|}{ Coef. } & \multirow{2}{*}{$\frac{\mathrm{DP}}{0,006}$} & \multirow{2}{*}{$\begin{array}{l}\text { Coef. } \\
0,015\end{array}$} & \multirow{2}{*}{\multicolumn{2}{|c|}{$\frac{\mathrm{DP}}{0,006}$}} \\
\hline $\begin{array}{l}\text { Contínuo de cor } \\
\text { da pele }\end{array}$ & 0,126 & * & & 0,208 & $* *$ & & & & & 0,028 & $* * *$ & & & & \\
\hline Anos de escolaridade & & & & & & & 1,482 & *** & 0,055 & & & & 0,103 & $* * *$ & 0,004 \\
\hline Homem & $-0,156$ & & 0,101 & 1,764 & $* * *$ & 0,385 & 1,995 & *** & 0,356 & 0,396 & *** & 0,030 & 0,412 & *** & 0,029 \\
\hline Idade & 0,126 & $*$ & 0,054 & 0,535 & ** & 0,202 & 0,347 & & 0,189 & 0,050 & ** & 0,016 & 0,036 & * & 0,015 \\
\hline Idade $^{2}$ & $-0,002$ & ** & 0,001 & $-0,005$ & * & 0,002 & $-0,002$ & & 0,002 & $-0,001$ & ** & 0,000 & 0,000 & * & 0,000 \\
\hline Status ocup. do pai (ISEI) & 0,045 & $* * *$ & 0,005 & 0,184 & $* * *$ & 0,021 & 0,117 & $* * *$ & 0,020 & 0,009 & $* * *$ & 0,001 & 0,004 & $* *$ & 0,001 \\
\hline Status ocup. da mãe (ISEI) & 0,021 & $* *$ & 0,007 & 0,099 & $* *$ & 0,034 & 0,067 & * & 0,031 & 0,003 & & 0,002 & 0,000 & & 0,002 \\
\hline Educação do pai & 0,175 & $* * *$ & 0,018 & 0,444 & $* * *$ & 0,072 & 0,184 & $* *$ & 0,067 & 0,034 & $* * *$ & 0,005 & 0,016 & $* *$ & 0,005 \\
\hline Educaçấo da máe & 0,273 & *** & 0,020 & 0,688 & $* * *$ & 0,081 & 0,284 & *** & 0,076 & 0,038 & *** & 0,006 & 0,010 & & 0,005 \\
\hline Estrutura familiar & 0,911 & $* * *$ & 0,120 & 1,894 & $* * *$ & 0,425 & 0,543 & & 0,398 & 0,101 & ** & 0,036 & 0,007 & & 0,034 \\
\hline Pais c/ casa própria & 0,517 & *** & 0,113 & 1,777 & *** & 0,423 & 1,011 & ** & 0,391 & 0,126 & $* * *$ & 0,034 & 0,073 & * & 0,032 \\
\hline Mãe trabalhava & $-0,399$ & $* * *$ & 0,103 & $-1,215$ & ** & 0,394 & $-0,623$ & & 0,366 & $-0,066$ & * & 0,031 & $-0,025$ & & 0,029 \\
\hline Norte (vs. Nordeste) & 0,796 & *** & 0,221 & 0,687 & & 0,774 & $-0,492$ & & 0,730 & 0,250 & $* *$ & 0,073 & 0,168 & $* *$ & 0,066 \\
\hline Sudeste ( $v s$. Nordeste) & 0,582 & $* * *$ & 0,133 & 0,304 & & 0,469 & $-0,558$ & & 0,437 & 0,617 & *** & 0,041 & 0,557 & $* * *$ & 0,039 \\
\hline Sul (vs. Nordeste) & 0,220 & & 0,155 & 0,049 & & 0,533 & $-0,278$ & & 0,487 & 0,534 & *** & 0,047 & 0,511 & $* * *$ & 0,043 \\
\hline $\begin{array}{l}\text { Centro-Oeste ( } v s . \\
\text { Nordeste) }\end{array}$ & 1,241 & $* * *$ & 0,214 & 1,965 & * & 0,831 & 0,125 & & 0,738 & 0,641 & *** & 0,061 & 0,513 & *** & 0,054 \\
\hline Área urbana até 15 anos & 1,946 & $* * *$ & 0,117 & 3,405 & $* * *$ & 0,402 & 0,521 & & 0,389 & 0,074 & * & 0,034 & $-0,127$ & $* * *$ & 0,034 \\
\hline Constante & $-0,279$ & & 1,245 & 3,549 & & 4,696 & 3,964 & & 4,398 & 3,762 & $* * *$ & 0,366 & 3,790 & $* * *$ & 0,350 \\
\hline $\mathrm{N}$ & 6886 & & & 6886 & & & 6886 & & & 6886 & & & 6886 & & \\
\hline F & 233 & & & 67,11 & & & 114,6 & & & 81,32 & & & 117,9 & & \\
\hline Prob. > F & 0 & & & 0 & & & 0 & & & 0 & & & 0 & & \\
\hline R-quadrado & 0,388 & & & 0,2201 & & & 0,343 & & & 0,199 & & & 0,291 & & \\
\hline
\end{tabular}

${ }^{*}<0,05 ;{ }^{* *}<0,01 ;{ }^{* * *}<0,001$

Fonte: Pesquisa Dimensóes Sociais das Desigualdades, 2008. Elaboração do autor. 
Um outro tema importante que os modelos permitem observar é a relação entre os efeitos de classe de origem e de raça nas chances de alcançar mais anos de escolaridade. Com o objetivo de descrever melhor essa relação podemos observar as probabilidades preditas de anos de educação para pessoas em diferentes categorias de raça e posiçóes no contínuo racial e as seguintes origens sociais: classe alta ("elite"), classe média alta, classe média e classe baixa. Os números para essas probabilidades preditas representam variaçóes que levam em conta todas as outras variáveis incluídas nos Modelos 1 e 2 da Tabela 3. Indivíduos com origem na classe alta foram definidos como aqueles cujos pais tinham dezesseis anos de escolaridade (universidade completa) e status ocupacional com valor 87 (equivalente as ocupaçóes de médico ou advogado). Com origem na classe média alta são aqueles cujos pais tinham onze anos de escolaridade (ensino médio completo) e status ocupacional com valor 54 (equivalente a ocupação de metalúrgico ou de secretária). Origem na classe média é definida por pais com oito anos de escolaridade (primário complete) e status ocupacional igual a 33 (equivalente ao de um carteiro ou garçom), Por fim, origem na classe baixa é definida por pais que não frequentaram escolar (zero ano de escolaridade) e com status ocupacional igual a 23 (equivalente ao de um trabalhador manual não qualificado).

Pessoas com origem na classe alta tem probabilidade predita de alcançar 3,62 anos de escolaridade a mais do que indivíduos com origens na classe média alta, 7,96 anos a mais do que pessoas com origem na classe média e 9,69 anos a mais do que aqueles com origem na classe baixa. Embora a desigualdade de classe seja enorme os modelos indicam que as vantagens relacionadas a raça ou cor continuam sendo válidas mesmo quando a classe de origem é levada em conta. Em cada uma dessas categorias de classe de origem os indivíduos classificados como branco/branco no contínuo racial têm em média 0,66 e 0,90 ano de escolaridade a mais do que aqueles que se autoclassificaram como pardo/pardo e preto/preto respectivamente. Várias outras posições no contínuo racial poderiam ter sido usadas nessa comparação, quanto mais clara e branca maiores as vantagens educacionais. Em suma, a desigualdade racial se adiciona à desigualdade de classe, embora a segunda permaneça sendo muito mais alta.

Além de analisar a desigualdade educacional, estimei modelos para explicar a mobilidade econômica em termos de status ocupacional e renda do trabalho. Os modelos para realização de status ocupacional (Modelos 3 e 4) sem levar em conta a educação alcançada pelos indivíduos também indicam que há estratificação racial. Entretanto, quando a educação alcançada é levada em conta a desigualdade racial se torna não significativa (Modelos 5 e 6). Esses resultados confirmam os encontrados em pesquisas anteriores na medida em que sugerem que a desigualdade racial no processo de estratificação é particularmente relevante no momento de adquirir mais anos de escolaridade (Silva, 1981). As conclusôes para renda do trabalho, no entanto, indicam a presença de desigualdade racial mesmo quando a educação é levada em conta, o que também havia sido observado em outros estudos (Idem).

Levando em conta todas as variáveis incluídas nos modelos, indivíduos que se autoclassificaram como brancos na questão fechada (Modelo 7) têm renda em média 132,2 reais mais alta do que indivíduos que se classificaram como pardos ou pretos. Mesmo quando a educação é incluída no modelo (Modelo 9) a desigualdade permanece alta, ou seja, brancos têm renda em média 45,7 reais mais alta do que pardos e pretos. Nesses dois últimos modelos não foram observadas diferenças estatisticamente significativas entre pardos e pretos. Os Modelos 8 e 10 replicam as mesmas análises usando a variável para o contínuo racial em vez de as variáveis categóricas para raça. Mais uma vez levando em conta todas as variáveis incluídas no modelo (Modelo 8), observa-se que indivíduos na posição mais clara da escala de contínuo racial (branco/branco) tinham renda em média 96,3 reais mais altas do que aqueles no meio do contínuo racial (pardo/pardo) e 153,1 reais mais alta do que aqueles no extremo mais escuro (preto/preto). Ao incluir a educação alcançada no modelo (Modelo 10) observamos uma diminuição da desigualdade, que, no entanto, permanece relevante uma vez que os mais claros (branco/branco) continuam tendo renda em média 27,6 reais mais alta do que os no meio (pardo/pardo) 
e 44,7 reais mais alta do que aqueles no extremo mais escuro (preto/preto). Mais uma vez, a variável continua para raça possibilita uma descrição mais precisa e detalhada da desigualdade do que a variável categórica. Em outras palavras, o uso da escala contínua permite observar que a desigualdade está espalhada ao longo desse contínuo e não é simplesmente dicotomizada entre os grupos raciais. Assim, sugiro que a dicotomia branco versus náo branco ou branco versus negro deveria ser usada com cautela e nunca deveria ser "essencializada".

Náo é apenas a desigualdade racial que permanece relevante, mesmo levando em conta a educaçáo alcançada. A desigualdade de classe, definida pelas características socioeconômicas dos pais dos respondentes, continua muito alta. Para entender melhor a combinaçáo entre desvantagens raciais e de classe de origem nas chances de alcançar níveis de renda mais altos e também os retornos educacionais em termos de renda alcançados por esses indivíduos, apresento na Figura 2 a renda média predita para pessoas com origem na classe alta e na classe média que completaram o primário ou a educaçâo superior, de acordo com os Modelos 9 e 10 (Tabela 2).

A Figura 2 mostra que os rendimentos variam enormemente entre pessoas com níveis educacionais distintos, mas também com origens de classe e classificaçóes raciais diferentes. Tendo em vista que o Modelo 10 não é linear (logaritimo da renda) os valores preditos para os retornos financeiros (renda do trabalho) à educação também não são lineares em termos de raça e origens de classe. Os efeitos de classe e raça são maiores para os níveis mais altos de escolaridade alcançada. Pessoas com educação primária e origem na classe média que se classificaram no extremo mais claro do espectro de cor (branco/branco) têm renda média prevista 47,5 reais acima dos que se classificaram no meio (pardo/pardo) e 77,1 reais acima dos que se autoclassificaram no extremo mais escuro (preto/preto). Em contraste, pessoas com educaçáo primária e origem na classe alta que se classificaram entre os mais claros (branco/branco) têm renda média predita 67,7 reais mais alta do que os que se classificaram no meio (pardo/pardo) e 109,8 reais mais alta do que os que se classificaram entre os mais escuros (preto/preto). No topo da hierarquia de estratificaçáo, os indivíduos que alcançaram educação universitária, que tinham origem na classe média e que se classificaram entre os mais claros (branco/ branco) tinham renda média predita 112,8 reais mais alta do que aqueles no meio da escala (pardo/ pardo) e 182,8 reais mais alta do que os classificados entre os mais escuros (preto/preto). Já as pessoas com educação superior e origem na classe alta que se classificaram entre os mais claros (branco/branco) tinham renda média 180,7 reais maior do que os que estavam no meio (pardo/pardo) e 260,4 reais maior do que os mais escuros de todos (preto/preto). Em outras palavras, a desigualdade de classe e de raça em termos de renda aumenta conforme aumenta o nível educacional alcançado. Esses resultados confirmam as evidências anteriormente apresentadas na literatura de que a desigualdade racial é maior nos estratos mais altos da estratificação social e menor nos mais baixos (Ribeiro, 2006).

As análises nesta seção confirmam que a desigualdade racial tem um efeito aditivo em relação à desigualdade em termos de classe de origem. Tendo em vista que a aparência é o que caracteriza a raça no Brasil, a medida do contínuo racial que desenvolvo e apresento ao longo das análises deste artigo pode ser considerada uma forma alternativa de entender e representar a desigualdade racial nos processos de mobilidade social no Brasil. Mais importante ainda, como mostro a seguir, é que minha abordagem permite discutir de forma consequente questôes relacionadas à ambiguidade da classificação racial no Brasil.

\section{Simulaçóes: o efeito do "embranquecimento"}

O fato de a classificaçáo racial no Brasil ser baseada na aparência facilita a ambiguidade, ou seja, é possível que pessoas com aparência racial muito semelhante se classifiquem como mais claras ou mais escuras ao responder as perguntas sobre raça ou cor. Uma hipótese normalmente aventada na literatura é a de que o "dinheiro embranquece" na medida em que pessoas em posiçôes mais altas no sistema de estratificação tendem a se ver e se apresentar como mais claras e brancas do que pessoas com características iguais, mas em posições 
Figura 2

Valor Esperado da Renda do Trabalho por Cor da Pele (Contínua e Categórica) Para Pessoas de Classe Alta e Classe Média com Educaçáo Superior e Educação Primária (Brasileiros Entre 30 e 64 Anos de Idade)

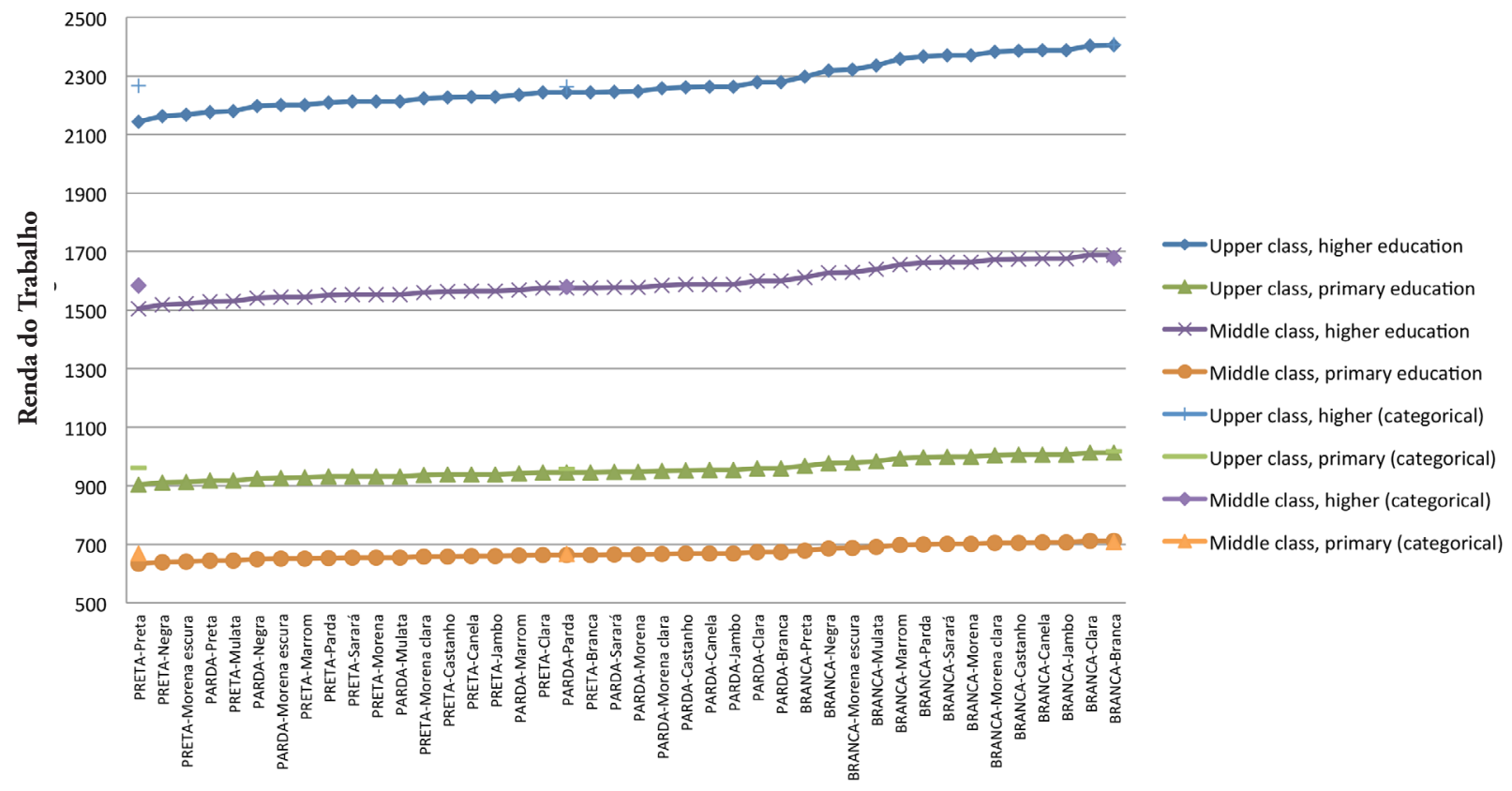

Fonte: Pesquisa Dimensóes Sociais das Desigualdades, 2008. Elaboração do autor

socioeconômicas mais baixas. Se essa hipótese for verdadeira, parte da associação entre a raça e as variáveis estudadas nesse artigo (educação, status ocupacional e renda) talvez estivesse sendo incorretamente estimada, porque aqueles que alcançaram mobilidade ascendente tendem a se "embranquecer”. Se isso estiver acontecendo, a verdadeira associação poderia ser muito menor ou até inexistente. Em outras palavras, haveria menos desigualdade racial do que indicam os modelos e análises apresentados na seção anterior. Uma pesquisa cuidadosa deve encontrar alguma maneira de testar quais seriam os efeitos desse possível "embranquecimento" nas taxas de desigualdade e mobilidade social. Nesse sentido, proponho uma análise de sensibilidade em que classifiquei arbitrariamente aqueles indivíduos que poderiam estar se "embranquecendo" em pontos mais escuros da escala racial. Mais especificamente, "escureci" (impus uma classificação racial mais escura) os indivíduos que se autoclassificaram em posiçóes mais propensas à ambiguidade no contínuo racial.

Mais especificamente, reclassifiquei os indivíduos entre as posiçóes branco/branco e pardo/pardo na escala racial (escores entre 3,8058 e -0,7133) em valores equivalentes à classificaçấo como pardo/ pardo (escore de -0,7267), bem como aqueles entre os pontos pardo/pardo e preto/preto (escores entre $-0,7295$ e -3,0086) em valores equivalentes à classificação preto/preto (escore de $-3,7181$ ). Em vez de reclassificar todas as pessoas em categorias intermediárias em posições mais "escuras", adotei esse procedimento apenas para os indivíduos em posiçôes mais altas na distribuição de renda. Em outras palavras, "escureci" as pessoas em posiçóes intermediárias no contínuo racial que estivessem primeiro entre os $1 \%$ mais ricos e, em seguida, entre os $5 \%$, $10 \%, 20 \%$, 30\%, 40\%, 50\%, 60\%, 70\%, 80\% e $90 \%$ mais ricos. Seguindo essa estratégia, escureci as pessoas mais ricas que poderiam estar "embran- 
quecendo com o dinheiro". Fiz isso em etapas desde os 1\% mais ricos até chegar aos $90 \%$ mais ricos.

Dessa forma, proponho uma metodologia que permite verificar qual o grau de "embranquecimento" que seria necessário para eliminar, ou diminuir significativamente, a desigualdade racial nas chances de mobilidade intergeracional. É óbvio que a seleção dos grupos de ricos $(1 \%, 5 \%, 10 \%, 20 \%$, $30 \%$ etc.) é arbitrária. ${ }^{9} \mathrm{O}$ objetivo dessas análises não é o de encontrar a desigualdade verdadeira, mas simplesmente testar os possíveis efeitos do "embranquecimento" nas estimativas de mobilidade social. Usando essa estratégia, puramente "contrafactual", é possível verificar qual seria o montante de "embranquecimento" que, se fosse revertido, eliminaria a desigualdade racial observada.

A Tabela 3 apresenta os resultados das análises sobre os efeitos do "escurecimento" dos mais ricos na mobilidade social em termos de anos de educação, status ocupacional e renda. Cada linha da Tabela 3 apresenta a porcentagem dos mais ricos que foi "escurecida" e as colunas apresentam os coeficientes do efeito (obtidos por diferentes modelos de regressão linear) da variável para o contínuo racial depois de "escurecer" os mais ricos. ${ }^{10}$ Como pode ser visto, o efeito da variável para o contínuo racial diminui até um certo ponto, a partir do qual começa a aumentar. Esse é o ponto de declínio máximo representando o mínimo de desigualdade que encontraríamos se as pessoas mais ricas estivessem se "embranquecendo" ao responder as perguntas sobre cor ou raça.

Para a mobilidade educacional, o máximo de diminuição da desigualdade racial que poderia estar acontecendo seria $14 \%$ se pelo menos $50 \%$ dos mais ricos estivessem se "embranquecendo". Para a mobilidade em termos de status ocupacional o máximo de diminuição seria de $31 \%$ se os $20 \%$ mais ricos estivessem se "embranquecendo"; para a mobilidade em termos de renda o máximo de diminuição do efeito da cor seria de $48 \%$ se os $50 \%$ mais ricos estivessem se "embranquecendo". Quando se leva em conta a educação alcançada pelos indivíduos, o máximo de diminuição no efeito de cor ou raça na mobilidade de renda seria $79 \%$ se os $60 \%$ mais ricos estivessem se "embranquecendo". Em outras palavras, se o processo de "embran- quecimento com o dinheiro" realmente existisse no Brasil, a desigualdade racial seria muito menor do que a atualmente observada, mas mesmo assim existiria desigualdade racial nas chances de mobilidade social.

Estudos recentes têm mostrado que a posição dos indivíduos e das famílias na hierarquia de estratificação social afeta sua classificação racial (Schwartzman, 2007; Silva, 1994; Telles, 2002). Esses resultados fazem com que as pesquisas sobre desigualdades raciais sejam duramente questionadas. Se o "dinheiro embranquece" e a "pobreza escurece", as diferenças ou desigualdades entre grupos raciais poderiam ser vistas como um simples artefato da dinâmica de classificação racial. Nessa seção, mostrei que mesmo que um processo tal como o de "embranquecimento" dos mais ricos aconteça, alguma desigualdade nas chances de mobilidade social entre pessoas com diferentes características raciais continuaria existindo.

\section{Conclusáo}

Embora os estudiosos das relaçóes raciais no Brasil reconheçam há muitos anos que as categorias raciais são baseadas na aparência e que podem variar ao longo de um contínuo que vai do mais escuro e negroide ao mais claro e caucasiano (a própria classificação do IBGE reconhece essa hierarquia ao usar os termos branco, pardo e preto), praticamente todas as evidências quantitativas sobre desigualdade racial são baseadas na dicotomia branco versus não branco ou na comparação de três categorias raciais (branco, pardo e preto). Essa maneira de usar a variável ajudou a mostrar que a desigualdade racial é alta e persistente ao longo do tempo. Esses resultados, no entanto, são frequentemente questionados por causa de uma outra característica das relaçóes raciais no Brasil: a ambiguidade da classificação racial e a possibilidade de "embranquecimento" dos mais ricos e daqueles com mobilidade ascendente. Tendo em vista que a classificação racial é baseada na aparência e definida nas interaçóes sociais, há espaço para que as pessoas se apresentem e sejam vistas pelas outras como "mais brancas" do que seriam 
Tabela 3

Simulaçóes Testando os Possíveis Efeitos do "Embranquecimento"

Mudanças nos Parâmetros Estimados para Diferentes Variáveis Dependentes Quando Categorias Intermediárias de Cor da Pele são Artificialmente Escurecidas para Pessoas em Diferentes Níveis de Status Socioeconômico Superior.

\begin{tabular}{llllll}
\cline { 2 - 5 } Modelos & $\begin{array}{l}\text { Anos de } \\
\text { escolaridade }\end{array}$ & Isei & $\begin{array}{l}\text { Isei }+ \\
\text { escolaridade } \\
\text { (n.s) }\end{array}$ & $\begin{array}{l}\text { Renda do } \\
\text { trabalho }\end{array}$ & $\begin{array}{l}\text { Renda do } \\
\text { trabalho + } \\
\text { escolaridade }\end{array}$ \\
\hline Modelo preferido* & 0,126 & 0,208 & 0,021 & 0,028 & 0,015 \\
\hline Escurecendo o 1\% mais rico & 0,126 & 0,207 & 0,020 & 0,028 & 0,015 \\
\hline Escurecendo os 5\% mais ricos & 0,123 & 0,185 & 0,004 & 0,025 & 0,012 \\
\hline Escurecendo os 10\% mais ricos & 0,120 & 0,163 & $-0,016$ & 0,023 & 0,011 \\
\hline Escurecendo os 20\% mais ricos & 0,114 & 0,142 & $-0,026$ & 0,020 & 0,009 \\
\hline Escurecendo os 30\% mais ricos & 0,112 & 0,149 & $-0,017$ & 0,018 & 0,007 \\
\hline Escurecendo os 40\% mais ricos & 0,109 & 0,152 & $-0,010$ & 0,016 & 0,004 \\
\hline Escurecendo os 50\% mais ricos & 0,109 & 0,162 & 0,000 & 0,015 & 0,003 \\
\hline Escurecendo os 60\% mais ricos & 0,113 & 0,183 & 0,015 & 0,015 & 0,003 \\
\hline Escurecendo os 70\% mais ricos & 0,115 & 0,181 & 0,012 & 0,016 & 0,004 \\
\hline Escurecendo os 80\% mais ricos & 0,117 & 0,194 & 0,020 & 0,017 & 0,005 \\
\hline Escurecendo os 90\% mais ricos & 0,128 & 0,232 & 0,042 & 0,024 & 0,011 \\
\hline
\end{tabular}

Fonte: Pesquisa Dimensões Sociais das Desigualdades, 2008. Elaboração do autor

Diminuiçáo Proporcional no Efeito da Cor da Pele

\begin{tabular}{lllll}
\hline Escurecendo o 1\% mais rico & $0 \%$ & $-1 \%$ & $-1 \%$ & $-2 \%$ \\
\hline Escurecendo os 5\% mais ricos & $-3 \%$ & $-11 \%$ & $-12 \%$ & $-20 \%$ \\
\hline Escurecendo os $10 \%$ mais ricos & $-5 \%$ & $-22 \%$ & $-18 \%$ & $-30 \%$ \\
\hline Escurecendo os $20 \%$ mais ricos & $-10 \%$ & $-31 \%$ & $-28 \%$ & $-44 \%$ \\
\hline Escurecendo os 30\% mais ricos & $-11 \%$ & & $-36 \%$ & $-58 \%$ \\
\hline Escurecendo os $40 \%$ mais ricos & $-13 \%$ & & $-45 \%$ & $-72 \%$ \\
\hline Escurecendo os 50\% mais ricos & $-14 \%$ & $-48 \%$ & $-78 \%$ \\
\hline Escurecendo os 60\% mais ricos & & & $-79 \%$ \\
\hline Escurecendo os 70\% mais ricos & & & \\
\hline Escurecendo os 80\% mais ricos & & & \\
\hline Escurecendo os $90 \%$ mais ricos & & & \\
\hline
\end{tabular}

* Modelos na Tabela 2; n.s. = não significantes.

Fonte: Pesquisa Dimensões Sociais das Desigualdades, 2008. Elaboração do autor 
se estivessem em posiçóes de classe mais baixas. Se esse tipo de processo social estiver ocorrendo, fica difícil ou impossível saber se os níveis de desigualdade racial observados são confiáveis. De fato, pesquisas recentes mostram que o processo de "embranquecimento" com o dinheiro realmente ocorre (Schwartzaman, 2007) e que diferentes maneiras de medir raça ou cor (dividir o contínuo racial em diferentes pontos) levam a avaliaçóes diferentes sobre os níveis de desigualdade racial (Loveman, 2011).

É um desafio para a pesquisa contemporânea reconciliar essas duas correntes de pesquisa, ou seja, é fundamental mostrar como a fluidez na classificação racial influencia nossa avaliação sobre a desigualdade racial. Isso é exatamente o que proponho no presente artigo: primeiro, medir a raça ou cor usando uma variável continua (em vez de variáveis categóricas) que vai do mais escuro até o mais claro, ou seja, usa vários pontos ao longo de um contínuo racial; segundo, usar essa nova medida do contínuo racial em modelos de mobilidade educacional, ocupacional e de renda. Comparei esses modelos com outros usando as variáveis categóricas tradicionais para raça. Assim, foi possível observar efeitos substanciais ao longo do contínuo, efeitos que são mais detalhados do que os geralmente obtidos quando as variáveis categóricas são usadas. Quanto mais escura for a pessoa, menores são suas chances de mobilidade ascendente nas hierarquias de estratificação social. A presença de desigualdade racial nas chances de mobilidade é bastante relevante, tendo em vista que os efeitos estão presentes mesmo quando diversas outras variáveis de controle são incluídas nos modelos. Por fim, fiz testes para verificar o que poderia estar acontecendo com a desigualdade racial se as pessoas mais ricas estivessem se "embranquecendo". Para realizar esses testes estimei todos os modelos de mobilidade social usando uma versão da variável para o contínuo racial em que as pessoas nos níveis de renda mais altos e em posiçóes raciais intermediárias foram arbitrariamente "escurecidas". Usando essa estratégia fui capaz de verificar em que medida a desigualdade racial teria diminuído se algum processo de "embranquecimento" dos mais ricos estivesse ocorren- do. Concluí que, apesar da ambiguidade classificatória, a estratificação racial é bastante significativa no Brasil contemporâneo.

Mesmo levando em conta diversas características das famílias de origem e a fluidez na classificação racial, os indivíduos mais escuros (mais pretos) têm chances menores de mobilidade em termos de educação e renda. Diferenças socioeconômicas entre brasileiros com diferentes características raciais são grandes e estão presentes ao longo do contínuo racial. Quanto mais clara e branca for a pessoa, maiores são suas chances de alcançar posiçóes mais altas no sistema de estratificação. Minhas análises mostram de forma contundente que essas diferenças estão presentes ao longo do contínuo racial e não apenas entre uma ou duas barreiras raciais. Em suma, argumentei ao longo do artigo que mensurar a raça usando uma variável continua é melhor do que usar as variáveis categóricas tradicionais e, o que é ainda mais importante, possibilita levar em conta os possíveis efeitos da ambiguidade racial (processo de "embranquecimento" por meio do dinheiro).

As desigualdades em termos de mobilidade social não são suficientes para mostrar a existência de discriminação racial. No entanto, o fato de haver desigualdade de renda ao longo do contínuo racial - mesmo quando levamos em conta diversas variáveis para medir as origens familiares das pessoas - é um forte indício de que os brasileiros mais escuros e negros de fato enfrentam discriminação no mercado de trabalho. Alternativamente, poderíamos dizer que as diferenças nas chances de mobilidade educacional e de renda entre indivíduos mais e menos escuros poderiam ser uma consequência de processos de acumulação de desvantagens nos quais pessoas mais escuras são sempre colocadas em posições mais baixas na estratificação social ao longo de seus ciclos de vida e das geraçóes. Esse processo também levaria às desigualdades nas chances de mobilidade que descrevi neste artigo. A discriminação no passado poderia levar as diferenças observadas no presente. Em uma sociedade conhecida por suas baixas taxas de mobilidade social a estratificação racial poderia ser uma consequência da reprodução de classe mesmo que não houvesse discriminação racial. Se os níveis de mobilidade de classe forem baixos e os 
indivíduos nos níveis socioeconômicos mais altos tendessem a se casar entre si, as diferenças de status socioeconômico entre indivíduos com diferentes características raciais no passado poderiam ser perpetuadas mesmo que não existisse discriminação no presente. De fato, mais pesquisas são necessárias para desvendar o papel que a discriminação no passado e no presente desempenha na desigualdade racial no Brasil contemporâneo.

As análises que apresentei neste artigo mostram que a desigualdade racial varia ao longo de um contínuo, e que o processo de "embranquecimento" dos mais ricos não pode ser considerado um fator que, se fosse revertido, mostraria que a desigualdade racial não existe. Minhas conclusóes, no entanto, implicam desafios para as políticas públicas que procuram atuar para diminuir a desigualdade racial. Se o contínuo racial for a maneira correta de se medir a desigualdade racial, como poderiam ser implementadas as políticas públicas para focalizar as populações mais afetadas? Se não há fronteiras claras e naturais entre grupos mutuamente excludentes, como as políticas públicas poderiam atingir as pessoas certas? É difícil responder essas perguntas, que certamente estão relacionadas com as controvérsias em torno das políticas para as populaçóes discriminadas no Brasil. Historicamente, as ideias do contínuo racial e da mistura racial têm sido usadas por pessoas que argumentam contra o fato de que há discriminação racial no Brasil e que são, portanto, contra as políticas de ação afirmativa. Em contraste, minhas análises mostram que há desigualdade ao longo do contínuo racial e em um contexto com altos níveis de miscigenação. Talvez as políticas para lutar contra a desigualdade racial devam ser indiretas, baseadas na classe de origem, ou entáo focalizar as pessoas mais escuras para as quais a ambiguidade racial é muito pequena. As pessoas muito escuras não têm como tirar vantagens da ambiguidade classificatória. De qualquer forma, os resultados apresentados neste artigo são desafiadores para os formuladores de políticas públicas. Embora a desigualdade esteja claramente presente ao longo do contínuo racial, o fato de ser muito difícil definir grupos categóricos torna mais difícil formular políticas sem ambiguidade.

Por causa dessas particularidades o estudo das relações raciais no Brasil mostra que a estratificação racial permanece mesmo em contextos com muita miscigenação e altos níveis de ambiguidade classificatória em termos de raça. A miscigenação e a ambiguidade classificatória são cada vez mais estudadas em outros países da América Latina e nos Estados Unidos (Telles, 2009; 2014). Nos Estados Unidos, por exemplo, os níveis crescentes de casamento inter-racial e a possibilidade de ambiguidade classificatória têm sido vistos como um novo aspecto das relaçóes raciais (Harris, 2002; Telles, 2009). Mais uma vez, o estudo das relaçóes raciais no Brasil parece ser relevante para pesquisadores em outras partes do mundo.

\section{Notas}

1 Embora a prática do "embranquecimento" pareça ser mais comum como estratégia de mobilidade ascendente, com a criação das políticas de ação afirmativa o processo reverso, de "escurecimento", também parece ter sido usado por estudantes que visam entrar na universidade (Marteleto 2012; Francis 2012).

2 Os modelos de regressão que usam a variável para o contínuo racial, que na verdade é um índice construído a partir da estimativa de escalas em outro modelo (log-linear, ver quarta seção deste artigo), podem estar sujeitos a incertezas estatísticas. Neste sentido, eu poderia ter apresentado o resultado de modelos de equaçóes estruturais que levam em conta o erro intrínseco presente na variável latente. No entanto, os resultados encontrados nos modelos de regressão (apresentados) e nos modelos de equaçóes estruturais (não apresentados) são praticamente idênticos, o que me levou a apresentar as regressóes lineares, que são de interpretação muito mais simples. Para uma discussão do uso de variáveis latentes, ver Hardy e Bryman (2004).

3 Nelson do Valle Silva me disse, em comunicação pessoal, que ele e Hasenbalg usaram os termos brancos e não brancos (pardos e pretos), em vez de brancos e negros, para enfatizar que essa classificação era uma limitação metodológica e não uma posição política.

4 Em 1976, a Pesquisa Nacional por Amostragem Domiciliar (PNAD) incluiu essas mesmas perguntas. Estimei o mesmo modelo log-linear que uso neste artigo usando uma tabela que cruza as perguntas, aberta e fechada, elaboradas a partir dos dados de 1976. Os resultados obtidos para 1976 e 2008 são muito semelhantes, e a correlação entre as duas escalas obtidas para o "continuo racial" é de 0,94. Leitores interessa- 
dos podem entrar em contato com o autor para obter essas análises.

5 108. Qual a cor da sua pele? (espontânea - registre a manifestação do entrevistado); 109. Considerando apenas os termos: branca, preta, parda, amarela e indígena, como o(a) sr(a). classificaria a sua cor ou raça? 1 ( ) Branca, 2 ( ) Preta, 3 ( ) Parda,4 ( ) Amarela, 5 ( ) Indígena.

6 Em um modelo (não apresentado) incluindo apenas a variável categórica para raça (sem todas as outras variáveis de controle) indivíduos brancos têm escolaridade predita de 1,38 anos de estudo a mais do que pretos ou pardos.

7 Em um modelo (não apresentado) incluindo apenas a variável para o contínuo racial (sem todos os controles) indivíduos classificados como branco/branco têm escolaridade predita de 1,26 anos a mais do que aqueles classificados como pardo-pardo e 2,11 anos de escolaridade a mais do que aqueles classificados como preto/preto.

8 Marteleto (2012) também identificou um processo de "escurecimento com a educaçáo" entre jovens de 17 e 18 anos no final dos anos de 2000. Embora esse fenômeno tenha um impacto significativo na diminuição histórica da desigualdade racial em termos educacionais, provavelmente não afeta a populaçáo que tinha entre 30 e 64 anos em 2008, tendo em vista que nessa faixa etária a estratégia de "escurecimento" para se favorecer das políticas de açáo afirmativa para entrar na universidade não faz mais sentido. Ou seja, essa população já passou da idade de competir por vagas na universidade. Sobre esse assunto, ver também o trabalho de Andrew M. Francis e Maria Tannuri-Pianto (2012).

9 Também testei outras formas de "escurecimento", ou seja, usei as variáveis para educação e para status ocupacional, bem como uma escala combinando renda, educação e status ocupacional. Todas essas estratégias levaram a resultados semelhantes.

10 Os modelos estimados não são apresentados aqui, mas podem ser obtidos com o autor.

\section{BIBLIOGRAFIA}

ALBA, Richard \& NEE, Victor. (2003), Remaking the American mainstream: assimilation and the new immigration. Cambridge, MA, Harvard University Press.
BAILEY, Stanley R. (2008), "Unmixing for race making in Brazil". American Journal of Sociology, 114: 577-614.

BLAU, P. \& SCHWATZ, J. E. (1984), Crosscuting social circles. Londres, Academic.

BLAU, P.; BLUM, T. C. \& SCHWARTZ, J. E. (1982), "Heterogeneity and intermarriage". American Sociological Review, 47: 45-62.

BURTON, Jonathan; NANDI, Alita \& PLATT, Lucinda. (2010), "Measuring ethnicity: challenges and opportunities for survey research". Ethnic and Racial Studies, 33: 1332-1349.

CARDOSO, Fernando Henrique and Octavio IANNI. (1960), Cor e mobilidade social em Florianópolis. São Paulo, Companhia Editora Nacional.

DEGLER, Carl. (1986), Neither black nor white: slavery and race relations in the United States and Brazil. Madison, WI, University of Wisconsin Press.

DUNN, Christopher. (2007), "The intergenerational transmission of lifetime earnings: evidence from Brazil". The B.E. Journal of Economic Analysis \& Policy, 7 (2): 1-42.

FERES JR., João. (2008), "Ação afirmativa: política pública e opinião". Sinais Sociais, 3: 38-77.

FRANCIS, Andrew M. \& TANNURI-PIANTO, Maria. (2013), "Endogenous race in Brazil: affirmative action and the construction of racial identity among young adults". Economic Development and Cultural Change, 61 (4): 731-753.

GANZEBOOM, H.; DE GRAAF, P. \& TREIMAN, D. (1992), "A standard International Socio-Economic Index of occupational status". Social Science Research, 21: 1-56.

GOODMAN, Leo. (1984), The analysis of cross classified data having ordered categories. Cambridge, MA, Harvard University Press.

HARDY, Melissa \& BRYMAN, Alan. (2004), Handbook of data analysis. Nova York, Sage.

HARRIS, David R. \& SIM, Jeremiah J. (2002), "Who is multiracial? Assessing the complexity of lived race". American Sociological Review, 67: 614-627.

HASENBALG, Carlos. (1979), Discriminação e desigualdades raciais no Brasil. Rio de Janeiro, Graal. 
SILVA, Nelson do Valle \& HASENBALG, Carlos A. (1988), Estrutura social, mobilidade e raça. Rio de Janeiro, Iuperj/Vértice.

(1999), "Race, schooling and social mobility in Brazil”. Ciência e Cultura, 51: 457-463. (1990), Estrutura, mobilidade e raça. Rio de Janeiro, Vértice.

SILVA, Nelson do Valle \& HASENBALG, Carlos A. (orgs.). (1992), Relaçóes raciais no Brasil contemporâneo. Rio de Janeiro, Rio Fundo.

HASENBALG, Carlos A.; LIMA, Marcia \& SILVA, Nelson do Valle. (1999), Cor e estratificação social. Rio de Janeiro, Contracapa.

HENRIQUES, Ricardo. (2001), "Desigualdade racial no Brasil: evolução das condiçôes de vida na década de 90". Texto para Discussão, n. 807. Rio de Janeiro, Ipea.

HOUT, M. (1983), Mobility tables. Beverly Hills, CA, Sage.

ISHIDA, Hiroshi. (2005), Social stratification and social mobility in late-industrializing countries. Tóquio, University of Tokyo.

KEITH, Verna M. \& HERRING, Cedric. (1991), "Skin tone and stratification in the black community". American Journal of Sociology, 97: 760-778.

KING, Gary; HONAKER, Jammes; JOSEPH, Anne \& SCHEVE, Kenneth. (2001), "Analyzing political science data: an alternative algorithm for multiple imputation". American Political Science Review, 95 (1): 49-69.

KING, Gary; TOMZ, Michael \& WITTENBERG, Jason. (2000), "Making the most of statistical analyses: improving interpretation and presentation". American Journal of Political Science, 44: 341-355.

LOVELL, Peggy \& WOOD, Charles H. (1998), "Skin Color, Racial Identity and Life Chances in Brazil". Latin American Perspectives, 25: 90-109.

LOVEMAN, Mara \& MUNIZ, Jeronimo O. (2007), "How Puerto Rico became white: boundary dynamics and intercensus racial reclassification". American Sociological Review, 72: 915-939.

LOVEMAN, Mara; MUNIZ, Jeronimo O. \& BAILEY, Stanley R. (2011), "Brazil in black and white? Race categories, the census, and the study of inequality". Ethnic and Racial Studies, 32 (1): 1-18.

MACHADO, Weverthon Barbosa. (2015), Dimensóes da estratificação social: status e classe no Brasil contemporâneo (criaçáa de um novo indice de status). Dissertação de mestrado, Rio de Janeiro, Uerj.

MARTELETO, Letícia. (2012), "Educational inequality by race in Brazil, 1982-2007: Structural changes and shifts in racial classification". Demography, 49 (1): 337-358.

MARX, Anthony. (1998), Making race and nation: a comparison of the United States, South Africa and Brazil. Cambridge, MA, Cambridge University Press.

MUNIZ, Jerônimo O. (2010), "Sobre o uso da variável raça-cor em estudos quantitativos". Revista de Sociologia e Politica, 18: 277-291.

. (2012), "Preto no branco? Mensuração, relevância e concordância classificatória no país da incerteza racial”. Dados: Revista de Ciências Sociais, 55: 251-282.

NOBLES, Melissa. (2000), Shades of citizenship: race and the census in modern politics. Stanford, CA, Stanford University Press.

NOGUEIRA, Oracy. ([1962] 1998), Preconceito de marca: as relaçóes racias em Itapetininga. São Paulo, Edusp.

OSORIO, Rafael Guerreiro. (2009), A desigualdade racial de renda no Brasil: 1976-2006. Tese de doutorado. Brasilia, UnB.

RIBEIRO, Carlos Antonio Costa. (2006), "Raça, classe e mobilidade social no Brasil". Dados: Revista de Ciências Sociais, 49: 833-873.

RIBEIRO, Carlos Antonio Costa \& SILVA, Nelson do Valle. (2009), "Cor, educação e casamento: tendências da seletividade marital no Brasil, 1960 a 2000". Dados: Revista de Ciências Sociais, 52: 7-51.

SALATA, André. (2016), "Uma nova abordagem empírica para a hierarquia de status no Brasil". Revista Brasileira de Ciências Sociais, 31 (92): 1-22.

SANSONE, Livio. (1996), "Nem somente preto ou negro: o sistema de classificação racial no Brasil que muda". Revista de Estudos Afro-Asiáticos, 18: 165-187. 
(2003). Blackness without ethnicity: construction race in Brazil. Nova York, Palgrave MacMilan.

SAPERSTEIN, Aliya. (2008), (Re)Modeling race: incorporating racial theory into survey research on inequality. Tese de doutorado, Berkeley, CA, University of California, Berkeley. . (2011), "Capturing complexity in the United States: which aspects of race matter and when?" Ethnic and Racial Studies, 35 (8): 1-19. SCHWARTZMAN, Luisa Farah. (2007), "Does money whiten? Intergenerational change in racial classification in Brazil". American Sociological Review, 72: 940-963.

SILVA, Nelson do Valle. (1981), "Cor e processo de realização sócio-econômica”. Dados: Revista de Ciências Sociais, 24: 391-409.

. (1985), "Updating the cost of not being white in Brazil", in P. Fontaine (org.), Race and Class Power in Brazil, Los Angeles, Center for Afro-American Studies/UCLA.

. (1987), "Distância social e casamento inter-racial no Brasil". Estudos Afro-Asiáticos, 14: 54-83.

(1992), "Estabilidade temporal e diferenças regionais no casamento inter-racial", in Nelson do Valle Silva e Carlos A. Hasenbalg (orgs.), Relaçóes raciais no Brasil contemporâneo, Rio de Janeiro, Rio Fundo.

(1994), "Uma nota sobre 'raça social' no Brasil”. Estudos Afro-Asiaticos, 26: 79-96.

. (1996), "Morenidade: modo de usar". Estudos Afro-Asiáticos, 30: 79-96.

TELLES, Edward E. (1992), "Residential segregation by skin color in Brazil". American Sociological Review, 57: 186-197.

(1993), "Racial distance and region in Brazil: the case of marriage among color groups". Latin American Research Review, 28: 141-62.

(1994), "Industrialization and racial inequality in employment: the Brazilian example". American Sociological Review, 59: 46-63.

(2002), "Racial ambiguity among the Brazilian population". Ethnic and Racial Studies, 25: 415-441.

(2004), Race in another America: the sig- nificance of skin color in Brazil. Princeton, NJ, Princeton University Press.

TELLES, Edward (org.). (2014), Pigmentocracies: ethnicity, race, and color in Latin America. Chapel Hill, NC, University of North Carolina Press.

TELLES, Edward E. \& MURGUIA, Edward. (1990), "Phenotypic discrimination and income differences among Mexican Americans". Social Science Quarterly, 71: 682-696.

TELLES, Edward E. \& SUE, Christina A. (2009), "Race mixture: boundary crossing in comparative perspective". Annual Review of Sociology, 35: 129-46.

TELLES, Edward E. \& LIM, Nelson. (1998), "Does it matter who answers the race question? Racial classification and income inequality in Brazil". Demography, 35: 465-474.

TELLES, Edward; FLORESB, René D. \& URREA-GIRALDOC, Fernando. (2015), "Pigmentocracies: educational inequality, skin color and census ethnoracial identification in eight Latin American countries". Research in Social Stratification and Mobility, 40: 39-58.

TORCHE, Florencia \& COSTA-RIBEIRO, Carlos. (2012), "Parental wealth and children's outcomes over the life-course in Brazil: a propensity score matching analysis". Research in Social Stratification and Mobility, 30 (1): 79-96.

VILLARREAL, Andrés. (2011), "Stratification by skin color in contemporary Mexico". American Sociological Review, 75: 652-678.

WEBER, M. ([1922] 1978), Economy and society: an outline of interpretative sociology. Berkeley, CA, University of California Press.

XIE, Yu \& GOYETTE, Kimberly. (1997), "The racial identification of birracial children with one Asian parent: evidence from the 1990 Census". Social Forces, 76: 547-570. 


\section{Apêndice: estatísticas descritivas}

\begin{tabular}{lllll} 
& \multicolumn{2}{c}{ Todos os indivíduos } & & Max \\
\cline { 2 - 5 } & Média & D. P. & Min & 16 \\
\hline Anos de escolaridade do responsável & 7,3 & 4,35 & 0 & 90 \\
\hline Status ocupacional do responsável & 35 & 14,40 & 19 & 53268 \\
\hline Renda do trabalho do responsável & 495 & 3,17 & 3 & 3,56 \\
\hline Contínuo de cor da pele & 1,40 & 2,04 & $-2,41$ & 1 \\
\hline Branco & 0,49 & 0,50 & 0 & 1 \\
\hline Pardo & 0,39 & 0,49 & 0 & 1 \\
\hline Preto (omitido) & 0,12 & 0,32 & 0 & 1 \\
\hline Sexo (homem=1; mulher=0) & 0,47 & 0,50 & 0 & 64 \\
\hline Idade & 46,5 & 9,5 & 30 & 4096 \\
\hline Idade2 & 2253,8 & 893,6 & 900 & 90 \\
\hline Status ocup. do pai & 31,52 & 12,62 & 18 & 1 \\
\hline Mãe trabalhava & 0,45 & 0,50 & 0 & 90 \\
\hline Status ocup. da mãe & 27,86 & 7,83 & 19 & 16 \\
\hline Educaçáo do pai & 3,39 & 3,71 & 0 & 16 \\
\hline Educaçáo da mãe & 3,00 & 3,50 & 0 & 1 \\
\hline Estrutura familiar & 0,75 & 0,44 & 0 & 1 \\
\hline Pais cl casa própria & 0,71 & 0,45 & 0 & 1 \\
\hline Residência urbana até 15 anos & 0,63 & 0,48 & 0 & 1 \\
\hline Norte & 0,05 & 0,21 & 0 & 1 \\
\hline Nordeste (omitido) & 0,22 & 0,42 & 0 & 0 \\
\hline Sudeste & 0,51 & 0,50 & 0 & 0 \\
\hline Sul & 0,17 & 0,38 & 0 & 1 \\
\hline Centro-Oeste & 0,05 & 0,23 & 0 & \\
\hline & & & 0 \\
\hline
\end{tabular}

Fonte: Pesquisa Dimensóes Sociais das Desigualdades, 2008. Elaboração do autor 


\section{CONTÍNUO RACIAL, MOBILIDADE SOCIAL E "EMBRANQUECIMENTO"}

\section{Carlos Antonio Costa Ribeiro}

Palavras-chave: Mobilidade social; Relaçôes de raça; Classificação racial; Desigualdade de oportunidades; Estratificação social.

Pesquisas sobre raça no Brasil têm, há bastante tempo, reconhecido que categorias raciais são baseadas em distinçóes de cores da pele ao longo de um contínuo preto-branco. Contudo, evidências quantitativas sobre desigualdade social são baseadas na dicotomia branco versus não-branco (pardo e preto) ou na categorização em trio (branco, pardo e preto). Esta maneira de utilizar a variável contribuiu para demonstrar os altos níveis de desigualdade racial. Este achado, entretanto, é frequentemente questionado devido a outro aspecto: a alta ambiguidade na classificaçáo racial e a possibilidade de "embranquecimento" com dinheiro ou com mobilidade social ascendente. Se esta última característica é verdadeira, é difícil fazer uma medição de desigualdade social que seja confiável. Para lidar diretamente com este problema, meço o "contínuo de cores da pele" através da combinação de respostas a uma pergunta aberta (de livre escolha para os respondentes) e a uma pergunta fechada (com categorias censitárias) sobre cores da pele. Implementei simulaçóes contrafactuais para avaliar os possíveis efeitos do "embranquecimento com dinheiro" em realizaçóes educacionais, ocupacionais e econômicas.

\section{RACIAL CONTINUUM, SOCIAL MOBILITY AND “WHITENING”}

\section{Carlos Antonio Costa Ribeiro}

Keywords: Social mobility; Race relations; Racial classification; Inequality of opportunities; Social stratification.

Research on race in Brazil has for a long time recognized that racial categories are based on skin color distinctions along a black-white continuum. However, quantitative evidences about racial inequality are mostly based on the white versus non-white (brown and black) dichotomy or on the threefold categorization (white, brown, and black). This way of using the variable contributed to show the high levels of racial inequality. This finding, however, has often been questioned because of another aspect: the high ambiguity in racial classification and the possibility of "whitening" with money or with upward mobility. If this last feature is true, it is hard to make a reliable measure of racial inequality. In order to deal directly with this dilemma, I measure the "skin color continuum" combining answers to an open question (respondents free choice) and to a closed question (census categories) about skin color. I implement counterfactual simulations to access the possible effects of "whitening with money" on educational, occupational and economic attainments.

\section{CONTINUUM RACIAL, MOBILITÉ SOCIALE ET «BLANCHIMENT»}

\section{Carlos Antonio Costa Ribeiro}

Mots-clés: Mobilité sociale; Relations raciales; Classification raciale; Inégalité d'opportunités; Stratification sociale.

Les recherches sur la race au Brésil considèrent, depuis longtemps, que les catégories raciales reposent sur des distinctions de couleur de peau selon un continuum noir-blanc. Néanmoins, des données quantitatives sur l'inégalité sociale reposent essentiellement sur la dichotomie entre le blanc et le non-blanc (mulâtre et noir) ou sur la catégorisation en trio (blanc, mulâtre et noir). Cette façon d'utiliser la variable a contribué à démontrer les niveaux élevés d'inégalité raciale. Cette conclusion est, par contre, souvent mise en doute en raison d'un autre aspect : la grande ambiguïté dans la classification raciale et la possibilité de " blanchiment " grâce à l'argent ou à l'ascension sociale. Cette dernière caractéristique s'avérant vraie, il est difficile de mesurer l'inégalité sociale de façon fiable. J'affronte ce problème en mesurant le « continuum des couleurs de peau " par la combinaison des réponses à une question ouverte (de libre choix pour les répondants) et à une question fermée (avec des catégories employées lors de recensements) sur la couleur de peau. J'ai mis en œuvre des simulations hypothétiques contrefactuelles pour évaluer les effets possibles du "blanchiment grâce à l'argent " en termes de réussites éducatives, occupationnelles et économiques. 